\title{
The Mediating Role of Pathological Worry in Associations Between Dissociative Experiences and Sleep Quality Among Health Staff
}

\author{
Abdullah Yıldırım, MD¹, Murat Boysan, PhD², Onur Yılmaz, MD \\ ${ }^{1}$ Department of Psychiatry, Van Yüzüncü Yıl University School of Medicine, Van, Turkey \\ 2Department of Psychology, Van Yüzüncü Yıl University Faculty of Social Sciences, Van, Turkey
}

\begin{abstract}
There has been a growing interest in determining the antecedents of the significant associations between dissociative symptomatology and sleep. The aim of this study was to investigate the mediation effect of a tendency to elicit uncontrollable and excessive worry on the relationship between dissociation and poor sleep quality among non-shift working health staff. Eighty-five participants with a mean age of $31.19 \pm 7.14$ (ranging from 18 to 54) involved within the study. The Penn State Worry Questionnaire (PSWQ), Dissociative Experiences Scale (DES), Pittsburgh Sleep Quality Index (PSQI) and a demographic questionnaire were administered. Mediation regression models were utilized to evaluate direct and indirect associations between worry, dissociation and sleep quality after controlling for age, gender, marital status, education, prior psychiatric disorders, familial loading and time spent watching TV series in a week. Regression models indicated that direct dose-response relationship between dissociative symptomatology and sleep quality was not statistically significant. However, indirect effects of dissociative symptoms though pathological worry were substantial. More specifically, we found that the DES total, absorption/ imaginative involvement and dissociative amnesia had significant indirect effects on poor sleep quality via excessive worry as measured by the PSWQ. We concluded that dissociative symptoms are indirectly associated with sleep through negative repetitive thoughts such as pathological worry. Therefore, new generation therapeutic approaches particularly mindfulness therapy should be considered in the first-line treatments of sleep disturbance.

Keywords: dissociation, repetitive thoughts, negative thinking, affect regulation, sleep disorders, avoidance model, sleepdissociation
\end{abstract}

\section{INTRODUCTION}

Repetitive thought about one's self, one's personal experiences and one's expectations is not a rare mental process in community population (Harvey, Watkins, Mansell, \& Shafran, 2004; Watkins, 2008). Repetitive

*Correspondence: yldrmabdullah@yahoo.com

Dr. Abdullah Yıldırım, Department of Psychiatry, Van Yüzüncü Yıl University School of Medicine, Van, Turkey

Phone: +90 4324445065 Fax: +90 4322167519

Received: 17 September 2017 Accepted: 25 October 2017

Sleep and Hypnosis

Journal homepage:

www.sleepandhypnosis.org

ISSN:1302-1192 (Print) 2458-9101 (Online) thought is an umbrella conceptualization bridging many psychological constructs together. In an extensive systematic review of extant literature, Watkins (2008) identified multitude of theoretical conceptualizations relevant to repetitive thought emerged in distinct research domains: depressive rumination (Conway, Csank, Holm, \& Blake, 2000; Conway, Mendelson, Giannopoulos, Csank, \& Holm, 2004; Erdur-Baker \& Bugay, 2012; NolenHoeksema, 1991, 2004; Özgülük, Baker, \& Bugay, 2012; Sonkur, Boysan, \& Kadak, 2016), rumination (Martin, Shrira, \& Startup, 2004; Martin \& Tesser, 1996), worry (Borkovec, Ray, \& Stober, 1998; Borkovec, Robinson, Pruzinsky, \& DePree, 1983), perseverative cognition (Brosschot, Gerin, \& Thayer, 2006; Brosschot, Piepera, \& 
Thayer, 2005; Pieper \& Brosschot, 2005), mental simulation (Pham \& Taylor, 1999; S. E. Taylor, Pham, Rivkin, \& Armor, 1998; S. E. Taylor \& Schneider, 1989), counterfactual thinking (Mandel, 2003; Roese, 1994, 1997; Roese \& Olson, 1993), defensive pessimism (Norem \& Cantor, 1986a, 1986b; Norem \& Chang, 2002; Spencer \& Norem, 1996), reflection (Trapnell \& Campbell, 1999), mind wandering (Smallwood, Fitzgerald, Miles, \& Phillips, 2009; Smallwood, O'Connor, Sudbery, \& Obonsawin, 2007), post-event rumination (Kashdan \& Roberts, 2007), positive rumination (Feldman, Joormann, \& Johnson, 2008; Johnson, McKenzie, \& McMurrich, 2008), and habitual negative self-thinking (Verplanken, Friborg, Wang, Trafimow, \& Woolf, 2007).

Worry has been widely recognized as primary characteristics of anxiety, and has been defined as 'a chain of thoughts and images, negatively affect-laden and relatively uncontrollable' (Borkovec, Robinson, Pruzinsky, $\&$ DePree, 1983, p. 10). The content of worry is typically related to future events that include the possibility of adverse outcomes (Sibrava \& Borkovec, 2006).

Worry is a mundane human experience and exhibits a continuum across normal population, without any discontinuity (Olatunji, Broman-Fulks, Bergman, Green, \& Zlomke, 2010; Ruscio, Borkovec, \& Ruscio, 2001). Nevertheless, there seems to be a robust dose-response relationship between intolerance of uncertainty and pathological worry characterized by excessive, perseverative and uncontrollable nature that leads to more negative consequences in emotional well-being among community-dwelling non-clinical populations (Buhr \& Dugas, 2006; Dugas, Freeston, \& Ladouceur, 1997; Dugas, Gosselin, \& Ladouceur, 2001; Dugas, Schwartz, \& Francis, 2004; Ladouceur, Gosselin, \& Dugas, 2000) and clinical samples (Dar, lqbal, \& Mushtaq, 2017; Yook, Kim, Suh, \& Lee, 2010). A significant proportion of theoretical foundation of avoidance theory of worry rests on Mowrer's (1947) two stage theory of fear: Classically conditioned fear is maintained by operantly conditioned avoidance of fear cues. Under this circumstances, avoidance of internal fear cues may well be an integral part of the onset and maintenance process of anxious disorder that lead to various theoretical conceptualizations such as fear of fear (Goldstein \& Chambless, 1978), anxiety sensitivity (Reiss, Peterson, Gursky, \& McNally, 1986; S. Taylor, 2014), and meta-worry (Wells, 2005). According to the avoidance model of anxiety, imagined or mental avoidance such as behavioral avoidance could result in a failure to extinct eliciting anxious symptomatology (Borkovec, Alcaine, \& Behar, 2004).

Sleep is a crucial part of human existence, development and emotion regulation (Agargun, Boysan, \& Hanoglu, 2004; Aydin et al., 2013; Boysan, 2016b; Boysan \& Kagan, 2016; Gulec et al., 2011; Gulec et al., 2013; Minkel et al., 2012; Selvi et al., 2010; Siegel, 2005b). A primary function of sleep is to ensure cortically fully functioning during wakefulness (Siegel, 2005a). Sleep is default to good sleep as a natural state, encompassing homeostatic and circadian process. It is assumed to have both plasticity, a term referring to the 'absorb and readjust' capacity of sleepwake cycle in response to variability in personal and situational factors, and automaticity, a term referring to involuntary nature of well-adjusted schedule (Espie, 2002). Sleep has crucial implications that people with poor sleep may be subject to poor social, occupational and educational functioning (Abdel-Khalek, 2009; BaHammam, Al-Faris, Shaikh, \& Saeed, 2006; Boysan, Güleç, Beşiroğlu, \& Kalafat, 2010; Boysan \& Kagan, 2016; Chiang, Arendt, Zheng, \& Hanisch, 2014; Engle-Friedman \& Riela, 2004; Gulec et al., 2013; Laakso et al., 1999; Lahl \& Pietrowsky, 2006, 2007; Martikainen et al., 2001; Schichl, Ziberi, Lahl, \& Pietrowsky, 2011).

It is widely recognized that cognitive process is central in development and maintenance of sleep problems (Hiller, Johnston, Dohnt, Lovato, \& Gradisar, 2015). The prolonged wakefulness is positively associated with increased sleep hemeostat drive and prolonged sleep deprivation leads to functional impairment. Insufficient sleep results in rebound effect, refers to a recovery sleep consisting of spending longer time in bed, proportionately more rapid eye movement (REM) and deeper slow-wave sleep (Carskadon \& Dement, 2011). However, habitually decreased nocturnal sleep has severe consequences on quality of life (Knutson, Spiegel, Penev, \& Van Cauter, 2007; Matos, Gaspar, Tomé, \& Paiva, 2016; Paiva, Gaspar, \& Matos, 2015; Zeitlhofer et al., 2000). Poor sleepers have 
more negative thoughts at bedtime relative to good sleepers (Kuisk, Bertelson, \& Walsh, 1989; Nicassio, Mendlowitz, Fussell, \& Petras, 1985; Van Egeren, Haynes, Franzen, \& Hamilton, 1983). Several models have been conceptualized to shed light on the scope of the cognitive processes implicated in sleep disturbance.

In the pioneer models of sleep problems personality features of patients with insomnia were of crucial importance. These studies identified a typical profile for insomniacs with a pronounced tendency to internalize problems. The prospect was that a predisposition to internalize conflicts would lead greater emotional activation which in turn may result in physiological hyperarousal, rendering people more vulnerable to sleep problems (Borkovec, 1982; Kales, Caldwell, Preston, Healey, \& Kales, 1976). The micro-analytic model of Morin (1993), a more advanced refinement from multifactorial and integrated conceptualization, presents three levels of arousal (cognitive, emotional and physiological) that result in hyper-arousal, dysfunctional cognitions, maladaptive sleep habits, and arousal generating consequences. The presumptions of the model accounts for how primary insomnia becomes autonomous from precipitating actors to have raised from. The pathway of the development and maintenance of sleep problems commence with excessive physiological activity interfering with the sleep which, in turn, generates intrusive thoughts related to hyper-arousal states and emotional reactions based on personality traits in response to hyper-arousal. Core sleep-related dysfunctional beliefs have been more profoundly crystallized by means of permanent negative sleep experiences and engrain maladaptive sleep habits. Of several cognitive distortions, catastrophizing and probability overestimation were placed emphasis in regard to insomnia (Adan, Fabbri, Natale, \& Prat, 2006; Boysan, Merey, Kalafat, \& Kağan, 2010; Espie, Inglis, Harvey, \& Tessier, 2000; Morin, Vallieres, \& Ivers, 2007; Ong, Ulmer, \& Manber, 2012)

The integrated psychobiology of inhibition of dearousal model of sleep problems articulates that individuals experiencing sleep problems, specifically insomnia, exhibit increased metabolic rate accompanied by sleep state misperception, slow-wave sleep deficiency, and hyper-arousal, suggesting that poor sleep may arise from cortical over-activity. According to the model good sleep is maintained by four interacting subsystems: sleepstimulus control, physiological de-arousal, cognitive dearousal and daytime facilitation in which sleep homeostasis, circadian timing, and sleep quality serve to maintain these processes in a reciprocal way. Insomnia is presumed to arise from acute inhibition of one or more processes that cause a failure of automated sleep activation and maintenance (Espie, 2002).

Two subsequent processes of sleep-interfering and sleep interpreting model holds that a variety of psychological processes including traumatic and other stressful life events, emotional conflicts, negative conditioning, affect regulation problems and worrisome thoughts may cause physiological, cognitive and emotional hyper-arousal to an extent which lead to sleep-interfering. Psychological factors resulting in sleep-interfering precedes sleeprelated dysfunctional cognitive attributions. Commencement of the interfering-interpreting process is bidirectional; however, a vicious cycle of these two processes reciprocally induces each other by means of escalation in hyper-arousal states that sleep-interfering evolve into a chronic condition of sleep disorder (Lundh, 2011; Lundh \& Broman, 2000). Drawn from the Lundh and Broman's (2000) conceptualization, meta-cognitive model places more importance to meta-cognitive appraisals in which sleep problems are attributed to inability to sleep instead of cognitive reactivity (Ong et al., 2014; Ong et al., 2012).

From the perspective of the cognitive model of Harvey and colleagues, maintenance of insomnia is a function of excessive cognitive processes that occur either during the day or at night. Problematic sleep-related cognitive processes include worry, selective attention and monitoring, misleading interpretations with respect to sleep and imparted daytime function, distorted beliefs about sleep, and maladaptive safety behaviours (Harvey, 2002). The model places importance on the catastrophizing, particularly catastrophic worry about the consequences of not sleeping which, in turn, is associated with strong negative affect and increased perception of threat (Harvey \& Greenall, 2003). Catastrophic worrisome 
thinking at bedtime is assumed to give rise to sympathetic arousal and thus anxiety which is similar to what occurs at times of distress in response to threat or harm (Harvey, 2006). Such hyper-arousal states cause a narrowed attention to the stimuli including potential threats related to sleep that compromises the capacity to monitor real situations and reality testing (Harvey, Tang, \& Browning, 2005; Tang, Anne Schmidt, \& Harvey, 2007). Recurrence of such experiences strengthen dysfunctional beliefs and attitudes about sleep that maintain the vicious cycle of sleep and sleep-related problems. Dysfunctional sleep habits and behaviours emerge in order to prevent the individual from negative consequences of not sleeping that contrarily make the fears sustained (Fairholme \& Manber, 2014; Hood, Carney, \& Harris, 2011).

Based on prior conditioning experiences of individuals Bootzin and colleagues proposed a stimulus control model in which sleep problems occur to the extent to which sleep-related stimuli generates alternative responses (e.g., worrying, being concerned about not sleeping) inconsistent with sleep behaviour (Bootzin, 1972; Bootzin, Lack, \& Wright, 1999; Bootzin \& Rider, 1997). Inasmuch as the learned associations between sleep-related stimuli and inconsistent responses are established and strengthened, they would be predictive of sleep dysregulation (Coutanche \& Thompson-Schill, 2012). Spielman's behavioral perspective, a reconciliation of biological and psychological approaches, proposes a dimensional model related to etiology of sleep problems: predisposing, precipitating and perpetuating factors (3 Ps). Biological (i.,e, a tendency to experience arousal), psychological (i.e., a disposition to delve into excessive pondering and worry), and social (i.e., inconsistent sleep schedule) aspects constitute predisposing factors. A tendency to interpret life situations threatening and distressfully reflects the precipitating aspect. Finally, perpetuating factors refers to counterproductive strategies to cope with sleep disturbance (i.e, saying bed without sleeping) (Riemann et al., 2010; Smith et al., 2002; Spielman, Caruso, \& Glovinsky, 1987). New environments with biological, psychological and social cues for activation of arousal are associated with a transitory improvement in sleep complaints which is conceptualized as 'reverse first- night effect', a phenomenon proposed why people sleep well in the first night in the laboratories (Harvey \& Tang, 2012). The reverse first-night effect appears reflecting the role of cognitive behavioral learning by means of the interaction between organism, environment and cognitive appraisals concerning sleep.

The neurocognitive model of sleep problems put in evidence biopsychological factors in understanding the antecedent of sleep disturbance. A concept of hyperarousal with a three dimensional construct encapsulating somatic, cognitive and cortical aspects that are intertwined with each other is assumed to central in the development and maintenance of insomnia. Somatic aspect of hyper-arousal refers to increased metabolic activity, cognitive aspect refers to a profusion of RT in terms of worry and rumination, and cortical hyper-arousal reflects increased activity recorded on electroencephalography (EEG), event-related potentials (ERP), or structural and functional neuroimaging (MRI and fMRI) (Bonnet \& Arand, 1995, 1997a, 1997b; Marques, Allen Gomes, Clemente, Santos, \& Castelo-Branco, 2015; Perlis, Giles, Mendelson, Bootzin, \& Wyatt, 1997; Perlis, Merica, Smith, \& Giles, 2001).

Bottom-up model focuses on genetic underpinnings of functional impairment in neurocircuitry mechanisms implicated in normal sleep-wake cycle. Although the model does not object to the precipitating and perpetuating factors such as RT, the model gives more prominence to the genetically determined predispositions based on the neural circuitry generally located in brainstem underlying the regulation mechanisms of sleepwake cycle (Riemann et al., 2010; Saper, Scammell, \& Lu, 2005). It is contended that even thought biological and neuropsychological mechanisms determining the regulation of sleep are receptive to environmental clues, people with only genetic susceptibility are conducive to develop and maintain sleep-related problems (Buysse, 2010; Marques et al., 2015; Riemann et al., 2010).

Evidence suggest that sleep problems are associated with pronounced inappropriate hyper-arousal states including high-frequency EEG activation, abnormal hormone secretion, greater whole body and brain metabolic activation, elevated heart rate and sympathetic 
nervous system activation day and night (Bonnet \& Arand, 2010). Nevertheless, individuals with sleep problems reported less control on their thought processes (Watts, East, \& Coyle, 1995), and were more prone to worrying that generally revolve around work-related or general mental activities (Watts, Coyle, \& East, 1994). Insomnia patients with comorbid generalized anxiety disorder had greater bedtime mental activity compared to insomniacs without comorbid disorder (Gendron, Blais, \& Morin, 1998). In a similar vein, a controlled study of pre-sleep cognitive activity among insomniacs conducted by Harvey (2000) reported that insomniacs were marked by being more focused on worry about unable to sleep and general worries compared to good sleepers. Thought suppression had paradoxical ramifications regardless of whether insomnia-afflicted or not. Thought suppress individuals reported longer sleep onset latency and poorer sleep quality than did non-suppress individuals (Harvey, 2000).

Continuity hypothesis postulates that sleep affect is not independent from the affect regulation during waking states of consciousness (Schredl, 2000, 2003, 2006, 2009). Some individuals are proposed to have a tendency to experience more intense and frequent nightmares regarding their temperament and personality (Kelly, 2017). Nightmares are considered as attempts to diminish negative affect arise from fear-related adverse experiences (Levin \& Nielsen, 2007). When an inability to keep threatening information a bay during sleep occurs or psychological escape is no longer possible, nightmares may reflect a rebound of a suppressed emotion-laden content. It was proposed that the dreaming process serve information processing by exposing the dreamer to the feared stimuli (Nielsen \& Levin, 2007). Nevertheless, regular disruption of the dream processing will ultimately keep the fear memory alive. Continued avoidance from distressing emotion-laden content during day and night will increase frequency and intensity of nightmares, as well as negative sleep and wake affect. In short, vivid and emotionally dysphoric dreams or nightmares reflects a failure of a fear-extinction function and is an indicator of emotion dysregulation. Keeping with the continuity hypothesis, an influential two- process model of dreaming proposed that 'affect load' as a consequence of dally variations in emotional pressure and 'affect distress' representing a tendency to experience events with high levels of negative reactivity determine dreaming process (Levin \& Nielsen, 2009).

Significant associations between sleep and dissociation have received increased attention in the literature. The term dissociation is used to describe a range of conceptualizations across different theoretical approaches (Boysan, 2016a; Braude, 2009; Van der Hart \& Dorahy, 2009; Vermetten, Dorahy, \& Spiegel, 2007). Considered along a continuum, it can be viewed as an adaptive coping strategy at milder levels to being akin to a form of experiential avoidance (Boysan, 2014a). On the other hand, pathological dissociation is viewed as a disruption in the normal integration of consciousness, memory, identity, emotion, perception, body representation, and motor behaviour (American Psychiatric Association, 2013). As a counterproductive defense against overwhelming emotions or adverse experiences, a number of studies demonstrated significant associations between traumatic experiences and dissociative symptomatology (Boysan, Goldsmith, Cavus, Kayri, \& Keskin, 2009; Kadak, Nasiroglu, Boysan, \& Aydin, 2013; Selvi et al., 2012). Dissociation is a multifaceted construct that factor analytic investigations have generally supported a three dimensional factor structure (Armour, Contractor, Palmieri, \& Elhai, 2014; Ross, Joshi, \& Currie, 1991; Sanders \& Green, 1994; Soffer-Dudek, Lassri, Soffer-Dudek, \& Shahar, 2015; Stockdale, Gridley, Balogh, \& Holtgraves, 2002): Absorption, depersonalization-derealization, and dissociative amnesia. The term "absorption" refers to a tendency to become highly immersed in a single experience accompanied by a narrowed attention that results in unawareness of other stimuli in the environment (Soffer-Dudek et al., 2015; Vogel, Spitzer, Barnow, Freyberger, \& Grabe, 2006). Dissociative amnesia refers to an inability to recall important autobiographical memory, particularly with a traumatic nature (American Psychiatric Association, 2013). Finally, depersonalizationderealization refers to estrangement to one's own body, aberrant body experiences, emotional and physical numbing and temporal distortions in perception and 
sensation (Hunter, Phillips, Chalder, Sierra, \& David, 2003; Sierra \& Berrios, 2000).

Dream recall frequency is a generic indicator of dream intensity (Blagrove \& Pace-Schott, 2010). High dissociators exhibit more frequent dream recall and greater dream intensity than did low dissociators (Yu, 2010). Women who were more prone to dissociation were more likely to recall their dreams; whilst men more prone to altered consciousness states had greater dream recall frequency (Suszek \& Kopera, 2005). Several studies have found dissociative absorption, which is generally considered as normal aspect of a dissociative tendency, was a significant correlate of dream recall frequency (Levin \& Young, 2002; Schredl, Jochum, \& Souguenet, 1997), but others have not (Levin, Fireman, \& Rackley, 2003). A metaanalysis of 24 dream recall studies concluded that absorption is not related to dream recall frequency per se, but rather to one's tendency to underestimate or overestimate their dream recall frequency (BeaulieuPrevost \& Zadra, 2007).

In an early case study addressing the relations between somnambulism and dissociation, eight cases with somnambulism referring to a state of sleepwalking had dissociative disorders or were strongly suspected to have dissociative psychopathology (Schenck, Milner, Hurwitz, $\&$ Bundlie, 1989). Dissociative amnesia and dissociative impairment in space and time orientation were conceptualized as an interface between waking and sleep consciousness, similar to sleepwalking (Mahowald \& Schenck, 2001). Barrett $(1994,1995)$ considered the similarity between dream characters and 'alter personalities' in case reports of multiple personality disorder. Significant overlaps between dreaming and dissociative consciousness have emphasized in elsewhere (Bob, 2004; Bob \& Louchakova, 2015). Another case study pointed out linkage between dissociation and cataplexy, a sudden episode of loss of muscle tone, which is central within the symptom clusters of narcolepsy, a sleep disorder characterized by an urge to fall asleep at inappropriate times (La Via \& Brewerton, 1996). Participants with a history of childhood sexual abuse reported heightened levels of dissociative symptomatology during the episodes of sleep paralysis
(Abrams, Mulligan, Carleton, \& Asmundson, 2008; McNally \& Clancy, 2005a, 2005b). Post-traumatic stress disorder (PTSD) patients with dissociative sub-type reported greater hypervigilance and sleep difficulties (Ginzburg et al., 2006).

Frequency of nightmares has consistently been found to be associated with severe dissociative symptomatology (Agargun, Kara, Ozer, Selvi, Kiran, \& Kiran, 2003; Agargun, Kara, Ozer, Selvi, Kiran, \& Ozer, 2003; Cheung, 2012). Semiz, Basoglu, Ebrinc, and Cetin (2008) conducted a case control study to examine whether dream anxiety is associated with childhood trauma, dissociative experiences, and sleep disturbance among 88 borderline patients and 100 gender-matched healthy controls. Patients who reported heightened dream anxiety had also more frequent childhood traumatic experiences, more severe dissociative symptoms, and poorer sleep quality. In a sample of 846 participants recruited from general population, Rek, Sheaves, and Freeman (2017) reported heightened levels of worry, depersonalization, hallucinatory experiences, and paranoia to be significant correlates of nightmare occurrence and severity after controlling for negative affect.

The term 'sleep experiences' coined by Watson (2001) implies a constellation of unusual sleep experiences, i.e., nightmares, vivid or recurrent dreams, hypnagogic hallucinations, dreams of falling or flying, arousals, and lucid dreams. High dissociators seem to be more receptive to stress-related cues and reacts psychologically that they reported greater sleep-related experiences in reaction to severe daily stressful events, which was conceptualized as arousal-sleep (Soffer-Dudek \& Shahar, 2011). Heightened levels of dissociation were significantly associated with unusual sleep experiences (e.g., nightmares, recurring dreams) but not with diurnal preferences (Giesbrecht \& Merckelbach, 2004).

Fantasy proneness refers to an excessive involvement in daydreaming and reveals significant overlap with a dissociative tendency (Rauschenberger \& Lynn, 1995). Fantasy proneness was significantly associated with dream disturbances such as dream disturbances such as nightmares, bad dreams, night terror-like symptoms, and dream anxiety among patients with borderline personality 
disorder which was suggested to serve prevent from emotional instability in reaction to disturbing dreams (Simor, Csóka, \& Bódizs, 2010). Based on the premise that dissociative experiences are the by-product of labile sleep-wake cycle (Watson, 2001), two structural equation model was tested. One of the tested models showed that unusual sleep experiences induce fantasy proneness and cognitive failures which in turn fuels dissociative experiences. The latter model demonstrated that trauma have significant effects on elevation of dissociative symptomatology both directly and indirectly via sleep impairment (van Heugten-van der Kloet, Merckelbach, Giesbrecht, \& Broers, 2014). Sleep experiences such as narcolepsy, vivid and unusual dreams, and deviant nocturnal experiences were significantly associated with dissociation and fantasy proneness (Giesbrecht \& Merckelbach, 2006). In keeping with the continuity hypothesis, another non-clinical study of sleep experiences reported anxiety and dissociative absorption were significant predictors of general sleep experiences. A subset of sleep experiences were significantly associated with suggestibility (Fassler, Knox, \& Lynn, 2006). Expanding these findings, Knox and Lynn (2014) evidenced for significant associations of sleep experiences with dissociation, fantasy proneness and schizotypy.

In an experimental design investigation into the individual differences in dissociative symptomatology are linked to resting electroencephalogram (EEG) parameters. Suppression in the alpha band and raised levels of delta and theta activity were typical in participants who reported high levels of dissociation; whilst resting EEG activity parameters were not significant correlates of sleep experiences (Giesbrecht, Jongen, Smulders, \& Merckelbach, 2006). Another study of dissociation among patients suffering from severe insomnia explored whether self-report measure of dissociation was related with sleep patterns as measured by EEG. Insomniacs had elevated levels of dissociative symptoms which had significant relationship with unusual sleep experiences and poor sleep quality. Dissociative symptoms were linked to both subjective and objective measures of sleep. Insomnia patients with greater levels of dissociation reported longer periods of REM sleep, more sleepiness at awakening, and less time spent awake during the night (Van Der Kloet et al., 2013).

Sleep deprivation can impinge on attention (Lim \& Dinges, 2008; Tomasi et al., 2009), memory (Chee \& Chuah, 2008; Chee \& Chuah, 2007), and executive function (Nilsson et al., 2005). Sleep deprivation is resulted in default mode network connectivity and anti-correlation during rest and task performance (De Havas, Parimal, Soon, \& Chee, 2012). In a pioneering experimental study of 1 night total sleep deprivation demonstrated that spontaneous and induced dissociative symptoms were stable during the daytime but increased during the night. As the sleepiness and elevations in dissociative symptoms came about mood deterioration occurred (Giesbrecht, Smeets, Leppink, Jelicic, \& Merckelbach, 2007). The effect was not mediated by an impairment in mood regulation, sleepiness preceded dissociative symptoms which was then followed by mood deterioration (Van der Kloet, Giesbrecht, \& Merckelbach, 2011). A longitudinal design study to investigate the relations between sleep and dissociation evaluated a mixed inpatient sample on arrival and 6 to 8 weeks later. Significant connections between sleep experiences and dissociative experiences were observed that alleviated levels of dissociative experiences were determined by decreases in narcoleptic experiences rather than insomnia. Authors concluded sleep hygiene may contribute to the treatment and prevention of dissociative psychopathology (van der Kloet, Giesbrecht, Lynn, Merckelbach, \& de Zutter, 2012). Similar findings were replicated in a more recent study that heightened dissociation in response to 1-night total sleep deprivation was strongly linked to increased Dehydroepiandrosteronesulfate (DHEA-S) (correlation was $r=0.80$ ), a hormone intimately dependent on circadian regulation and implicated in neuroprotection, neuronal plasticity and excitability (Selvi, Kilic, Aydin, \& Guzel Ozdemir, 2015). Selvi et al. (2017) found that even though direct relations between circadian rhythm and dissociation was not substantial, indirect relation by means of insomnia severity was significant. This finding can be interpreted in a way that sleep problems occurring as a function of eveningness circadian preferences may fuel dissociative symptomatology. Another study concerning dissociative 
experiences emerged from sleep abnormalities, van Heugten-van der Kloet, Giesbrecht, and Merckelbach (2015) randomly assigned fifty-six healthy individuals to an experimental and a control group. The experimental group deprived of sleep in a laboratory. Sleepiness, mood and dissociative symptoms were measured repeatedly in both groups. Sleep deprivation was predictive of an increase in dissociative symptoms which was mediated by general distress. Sleepiness preceded escalation of dissociative symptoms and mood deterioration, in which sleepiness and dissociation were high during the night. Sleep-deprived high dissociators revealed impaired capacity to memorize emotional material (van Heugtenvan der Kloet et al., 2015).

In recent years, dissociation as an altered consciousness state has been related to sleep abnormalities. Most of the research have had a central focus on alterations in levels of dissociation as a function of sleep-related experiences, nevertheless, attempts to identify the risk for detrimental influences as a predictor of sleep problems have relatively been scarce. Furthermore, dissociation is a multifaceted construct; however, research on sleep-dissociation have largely relied on relations with overall dissociative tendency but not aspects of dissociative experiences. Soffer-Dudek et al. (2017) examined whether the fluctuations on dissociative tendency prospectively predict sleepiness following partial and total sleep loss and recovery sleep. Dissociative absorption was found to be a crucial antecedent of sleepiness following either sleep loss or recovery sleep. On the other hand, hyperarousal states arise from worrisome thoughts seems to play in poor sleep experiences. Although worry has long been recognized as a significant antecedent of sleep problems, to date, the relationship between dissociative symptoms and worry have received almost no attention in the literature. To the best of our knowledge, intense dissociative experiences may increase the alertness to stimuli that in turn increase excessive, uncontrollable and perpetual worry. Dissociative symptomatology may be linking to sleep impairment through pathological worry. The aim of this study was to investigate direct and indirect associations between three dimensions of dissociation, pathological worry and sleep quality.

\section{METHOD}

\section{Participants}

The study was announced at the hospital clinics and eighty-five health staffs who were working at Yüzüncü Yll University Education and Research Hospital volunteered to participate in the study. The mean age was 31.19 (SD \pm 7.14$)$, ranging from 18 to $54.51 .8 \%$ of the sample were female, $48.2 \%$ were married, $8.2 \%$ reported prior psychiatric disorder, and $2.4 \%$ had a history of psychopathology among first-degree relatives. The mean time spent watching TV series during a week was 3.59 $(S D \pm 3.13)$. All participants were informed about the purposes and procedures of the study. Written informed consent was provided by each volunteer before the psychometric battery set was administered. The psychometric instrument set contained self-administered scales and each participant completed the tests in a silent

Table 1. Socio-demographic characteristics

\begin{tabular}{|c|c|c|c|c|}
\hline Age & (mean, SD) & & 31.19 & 7.14 \\
\hline \multirow[t]{2}{*}{ Gender } & $(n, \%)$ & Female & 44 & $51.76 \%$ \\
\hline & $(n, \%)$ & Male & 41 & $48.24 \%$ \\
\hline \multirow[t]{2}{*}{ Marital status ${ }^{\ddagger}(\mathrm{n}, \%)$} & $(n, \%)$ & Married & 41 & $48.24 \%$ \\
\hline & $(n, \%)$ & Single & 44 & $51.76 \%$ \\
\hline \multirow[t]{4}{*}{ Education (n, \%) } & $(n, \%)$ & Primary school & 2 & $2.35 \%$ \\
\hline & $(n, \%)$ & Secondary school & 5 & $5.88 \%$ \\
\hline & $(n, \%)$ & High school & 23 & $27.06 \%$ \\
\hline & $(n, \%)$ & College & 55 & $64.71 \%$ \\
\hline Prior psychiatric disorder & $(n, \%)$ & & 7 & $8.24 \%$ \\
\hline History of family psychopathology & $(n, \%)$ & & 2 & $2.35 \%$ \\
\hline Watching TV series (hrs/week) & (mean, SD) & & 3.59 & 3.13 \\
\hline
\end{tabular}

Note. $\$ 3$ widowed participants (3.5\%) and 5 divorced participants are merged into single marital status group. 
room at psychiatry service. Socio-demographic characteristics of the sample are presented in Table 1.

\section{Instruments}

The Penn State Worry Questionnaire (PSWQ), Dissociative Experiences Scale (DES), Pittsburgh Sleep Quality Index (PSQI) and a demographic questionnaire were administered to participants.

\section{Dissociative Experiences Scale (DES)}

The DES originally measures dissociation on a continuum ranging from minor dissociative experiences, an immense involvement in external experience or internal imagery and of daytime dreaming (nonpathological dissociation) to pathological forms of dissociation (Holmes et al., 2005; Putnam, 1997). The DES consists of 28 self-report items that are rated on scale ranging from 0 to 100 , which are tapping onto three dimensions: absorption /imaginative involvement, amnesia, and depersonalization / derealization (Ross, Ellason, \& Anderson, 1995). A DES score of 30 and higher is indicative of pathological dissociation (Boysan, 2014b; Putnam et al., 1996). The DES has good validity and reliability, and good overall psychometric properties (Carlson et al., 1993).The Turkish version of the scale has reliability and validity as good as its original form, with a Cronbach's alpha of $a=0.91$ and test-re-test correlation coefficient of $r=0.78$ (Yargic, Tutkun, \& Sar, 1995).

\section{Pittsburgh Sleep Quality Index (PSQI)}

The Pittsburgh Sleep Quality Index (PSQI) is a reliable and valid instrument assessing sleep quality and disturbances over a 1-month time interval (Buysse, Reynolds, Monk, Berman, \& Kupfer, 1989). The measure consists of 19 self-report questions. The screening tool discriminates well poor from good sleepers, and is an excellent general screening measure of sleep disturbances. The Turkish version of the PSQI adapted by Agargun, Kara, and Anlar (1996).

\section{Penn State Worry Questionnaire (PSWQ)}

The PSWQ is a widely used measure of excessive and uncontrollable worry (Meyer, Miller, Metzger, \& Borkovec, 1990). It consists of 16 items, which are rated on fivepoint scale. The measure yields a total score ranging from 16 to 90 . Evidence from various clinical and nonclinical groups supports the reliability, unidimensional structure, and convergent and discriminant validity of the PSWQ (Boysan \& Kiral, 2016; Brown, Antony, \& Barlow, 1992; Kağan, 2011; Yilmaz, Gencoz, \& Wells, 2008). The Turkish version was demonstrated to have good reliability and validity (Boysan, Keskin, \& Besiroglu, 2008).

\section{Statistical Analysis}

We began computing descriptive statistics for sociodemographic characteristics of the sample. Pearson correlation coefficients between scale scores were computed. Four mediation regression analyses were run in which total and sub-scale scores of the DES were independent variables. Total DES, absorption /imaginative involvement, amnesia, and depersonalization / derealization were regressed onto PSQI global in which the relations between dissociative symptoms and sleep were mediated by PSWQ scores. The statistical significance threshold was held at $p<0.05$.

\section{RESULTS}

Using Pearson product-moment correlation coefficients, as can be seen in Table 2, we found significant

Table 2. Pearson correlation coefficients between scale scores

\begin{tabular}{|c|c|c|c|c|c|c|}
\hline & 1 & 2 & 3 & 4 & 5 & 6 \\
\hline 1. Dissociative Experiences Scale & 1 & & & & & \\
\hline 2. Absorption/Imaginative Involvement & $0.956 * *$ & 1 & & & & \\
\hline 3. Amnesia & $0.898 * *$ & $0.777 * \star$ & 1 & & & \\
\hline 4. Depersonalization/Derealization & $0.942 * \star$ & $0.835 * *$ & $0.837 * \star$ & 1 & & \\
\hline 5. Penn State Worry Questionnaire & $0.405 * *$ & $0.416 * *$ & $0.393 * *$ & $0.322 * *$ & 1 & \\
\hline 6. Pittsburgh Sleep Quality Index Global & 0.268 * & 0.269 * & 0.244 * & 0.237 * & $0.366 * *$ & 1 \\
\hline
\end{tabular}


correlations between total and subscales of the DES, PSWQ and PSQI.

Using indirect mediation regression model approach proposed by Preacher and Hayes (2008), we evaluated the associations between dissociative symptomatology and sleep quality mediated by pathological worry. We run four sequential mediator regression analyses in which the DES total and three sub-scales of the DES were in turn independent variables in each model. Dimensions of dissociative experiences regressed on sleep quality as measured by the PSQI via pathological worry rated on the PSWQ after controlling for age, gender, marital status, education, prior psychiatric disorders, familial loading and time spent watching TV series per week.

In the first regression analysis, we found that the model had substantial $F$ value $\left(F(9,75)=3.300, p=0.002 ; R^{2}=\right.$ $0.28)$. Even though the direct influence of dissociative symptomatology on the PSQI was not significant $(\beta=0.09$ $t=0.806 p=0.423$ ), the DES total was indirectly associated with poor sleep quality via pathological worry (Boot= $0.19 ; 95 \%$ Confidence Interval $=0.046-0.346$ ). Covariates age, gender, education, prior psychiatric disorders, familial loading and time spent watching TV series did not reveal a significant influence on the PSQ global scores, with an exception of marital status that single participants reported poorer sleep quality $(\beta=0.55$ $t=2.421 p=0.018$ ). Findings are represented in Figure 1 .

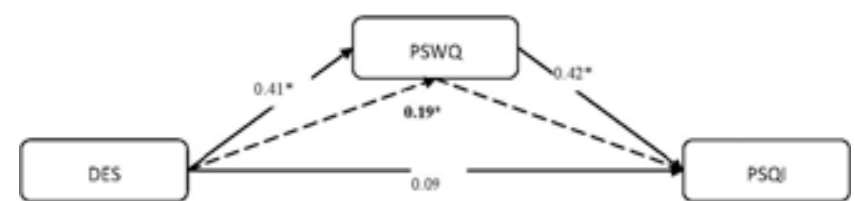

Figure 1: Mediation regression of the Dissociative Experiences Scale total on sleep quality through pathological worry after controlling for after controlling for age, gender, marital status, education, prior psychiatric disorders, familial loading and time spent watching TV series per week. The indirect effect is boldfaced. $(*: p<0.05)$

DES= Dissociative Experiences Scale; $P S W Q=$ Penn State Worry Questionnaire; PSQI= Pittsburgh Sleep Quality Index

In the second regression analysis, we regressed Absorption / Imaginative Involvement subscale of the DES on the PSQI global through pathological worry as measured by PSWQ. It was observed that the model had substantial $F$ value $\left(F(9,75)=3.272, p=0.002 ; R^{2}=0.28\right)$. The direct influence of absorption on the PSQI was not significant ( $\beta=0.08 \mathrm{t}=0.685 \quad p=0.496)$, Absorption / Imaginative Involvement subscale of the DES was indirectly associated with poor sleep quality via pathological worry (Boot $=0.21 ; 95 \%$ Confidence Interval $=0.044-0.371)$. Covariates age, gender, education, prior psychiatric disorders, familial loading and time spent watching TV series did not reveal a significant influence on the PSQI global scores, with an exception of marital status that single participants reported poorer sleep quality $(\beta=0.55 \mathrm{t}=2.413 p=0.018)$. Findings are presented in Figure 2.

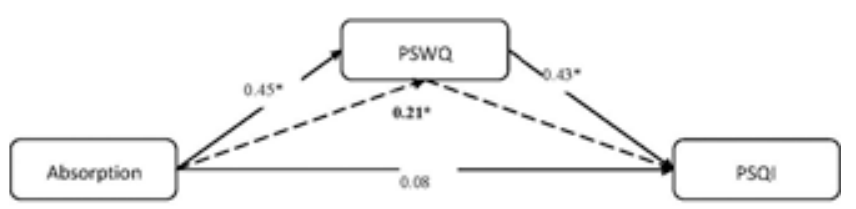

Figure 2: Mediation regression of Absorption / Imaginative Involvement subscale of the Dissociative Experiences Scale on sleep quality through pathological worry after controlling for age, gender, marital status, education, prior psychiatric disorders, familial loading and time spent watching TV series per week. The indirect effects is boldfaced. (*:p<0.05)

DES= Dissociative Experiences Scale; PSWQ= Penn State Worry Questionnaire; PSQI= Pittsburgh Sleep Quality Index

In the third regression analysis, we regressed dissociative amnesia subscale of the DES on the PSQI global through pathological worry as measured by PSWQ. It was observed that the model had substantial $F$ value $(F$ $\left.(9,75)=3.353, p=0.002 ; R^{2}=0.29\right)$. The direct effect of amnesia on the PSQI was not significant $(\beta=0.11 \mathrm{t}=0.995$ $p=0.323)$; in contrast, the dissociative amnesia was indirectly associated with poor sleep quality via pathological worry (Boot= 0.16; 95\% Confidence Interval $=0.048-0.334)$. Covariates age, gender, education, prior psychiatric disorders, familial loading and time spent watching TV series did not reveal a significant influence on the PSQI global scores, with an exception of marital status that single participants reported poorer sleep quality $(\beta=0.57 t=2.515 p=0.014)$. Findings are presented in Figure 3. 


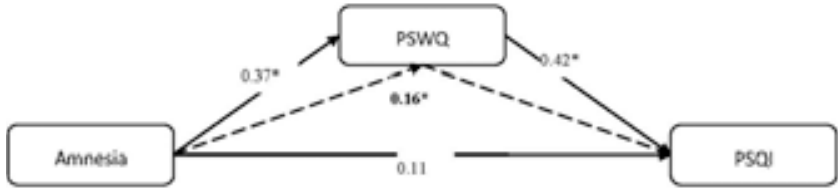

Figure 3: Mediation regression of amnesia subscale of the Dissociative Experiences Scale on sleep quality through pathological worry after controlling for age, gender, marital status, education, prior psychiatric disorders, familial loading and time spent watching TV series per week. The indirect effect is boldfaced. $(*: p<0.05)$

DES= Dissociative Experiences Scale; $P S W Q=$ Penn State Worry Questionnaire; PSQI= Pittsburgh Sleep Quality Index

In the forth regression model, we regressed depersonalization/derealization subscale of the DES on the PSQI global through pathological worry as measured by PSWQ. It was observed that the model had substantial $F$ value $\left(F(9,75)=3.296, p=0.002 ; R^{2}=0.28\right)$. Nevertheless, the direct effect of depersonalization/ derealization on the PSQI was not significant $(\beta=0.09$ $\mathrm{t}=0.787 p=0.593)$, as well as the indirect effect via pathological worry (Boot $=0.14 ; 95 \%$ Confidence Interval $=-0.004-0.297)$. Covariates age, gender, education, prior psychiatric disorders, familial loading and time spent watching TV series did not reveal a significant influence on the PSQI global scores, with an exception of marital status that single participants reported poorer sleep quality $(\beta=0.54 \mathrm{t}=2.398$ $p=0.019)$. Findings are presented in Figure 4 .

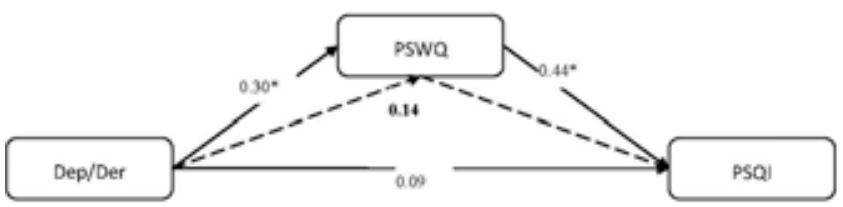

Figure 4: Mediation regression of depersonalization/ derealization subscale of the Dissociative Experiences Scale on sleep quality through pathological worry after controlling for age, gender, marital status, education, prior psychiatric disorders, familial loading and time spent watching TV series per week. The indirect effect is boldfaced. $(*: p<0.05)$

Dep/Der $=$ Depersonalization $/$ Derealization subscale of the Dissociative Experiences Scale; $P S W Q=$ Penn State Worry Questionnaire; $P S Q I=$ Pittsburgh Sleep Quality Index

\section{DISCUSSION}

The main aim of this study was to explore whether dissociative symptomatology significantly contribute to poor sleep quality through heightened levels of pathological worry. More specifically, we speculate that participants who were more prone to a dissociative tendency which is intrusive and imaginative in nature will engage in more worrisome thoughts marked by being mainly verbal compared to intrusive thoughts to draw their attention away. However, this engagement will not facilitate falling sleep rather the interaction effect of dissociation and worry will result in deterioration of sleep. Considering the facets of dissociative symptomatology, it was arguably expected a larger effect of dissociative absorption and imaginative involvement on sleep quality through pathological worry. In line with our hypothesis, the current data confirmed our hypotheses that proneness to dissociation particularly dissociative absorption indirectly contributed to poor sleep by means of heightened worrisome thoughts.

The most salient finding of the present data can be cataloged as follows. We highlighted and extended the robust link between dissociative symptoms and sleep that has been documented on a number of studies (Agargun, Kara, Ozer, Selvi, Kiran, \& Kiran, 2003; Agargun, Kara, Ozer, Selvi, Kiran, \& Ozer, 2003; Koffel \& Watson, 2009; Selvi et al., 2017; Soffer-Dudek \& Shahar, 2011; SofferDudek et al., 2017; Van Der Kloet et al., 2013; van der Kloet, Giesbrecht, et al., 2012; Van der Kloet et al., 2011; van der Kloet, Merckelbach, Giesbrecht, \& Lynn, 2012; van Heugten-van der Kloet et al., 2015; van Heugten-van der Kloet et al., 2014; Watson, 2001). Second we demonstrated that interaction between dissociation and worry play role in sleep disturbance that the direct relations between dissociative symptomatology and sleep quality fell short of significance when the relation was moderated by pathological worry. Finally, the current data provides a preliminary evidence and reflects a refinement of the previous findings with respect to the relations between dissociation and worry in relation to sleep disturbance. 
Dissociation and particularly REM sleep appear to have a deal of common neurophysiological underpinnings that disturbance in one of these psychological mechanisms may impinge on the other due to the premise that both belong to a common domain. Pathological dissociative experiences arise as a maladaptive affective avoidance or affect shutdown in the face of traumatic exposure (Lanius, 2015). Over-activation of frontal areas in the brain result in a dampening of sympathetic system and reduced emotional experiencing that suppress limbic activity implicated in emotional and cognitive information processing (Lanius et al., 2010; Nicholson et al., 2015). As with the dissociative process, frontal areas relatively deactivate limbic system during rapid eye movement (REM) sleep (Desseilles, Dang-Vu, Sterpenich, \& Schwartz, 2011). The premise that the REM sleep plays in emotional memory formation (Crick \& Mitchison, 1995; Walker \& van der Helm, 2009). Drawing in evidence as findings of Van Der Kloet et al. (2013) that longer REM sleep periods and less time spent awake at night among high dissociators, in which alterations in objective and subjective measures of sleep as a function of dissociation may be attributed to a somewhat rebound effect. In comparison to waking states, REM dreaming is more vivid and hyper-associational that remote memory material becomes more accessible during the REM sleep (Llewellyn, 2013). In response to stressful events or adversities, elevated levels of dissociation and alterations in sleep pattern both seem to serve facilitation of emotional information processing when the memory is emotion-laden in nature (Oathes \& Ray, 2008; Walker \& van der Helm, 2009).

The amygdala, medial prefrontal cortex, hippocampus, and anterior cingulate cortex implicate in the neurophysiology of dream function and nightmare production. Amygdala is central for emotional regulation during both sleeping and waking as well as fear conditioning. Medial prefrontal cortex takes part in fear extinction by selective gating within amygdala. Hippocampus involves within encoding and consolidation of the episodic memories. Finally, anterior cingulate is implicated in distress and separation anxiety (Levin \& Nielsen, 2007; Nielsen \& Levin, 2007). Dreaming mostly occurs in REM sleep that seems to be primed to activate these systems. According to an influential model of dreaming, it serves fear-memory extinction function by three processes: memory element activation, memory element recombination and emotional expression. The memory-element activation refers to the retrieving of a wide range of memories during dreaming. The memoryelement recombination is responsible for the assembly of isolated memory units into a coherent flow of dream imagery. The emotional expression maximizes the involvement of neural structures to down regulate negative emotional content. 'Affect load' refers to accumulation of stressful events that interferes with one's capacity to regulate emotions. 'Affect distress' was identified as a tendency to experience heightened distress in response to emotional stimuli. Occasional nightmares without excessive accompanying distress during the following day is considered to be a psychological reactions to relatively isolated incidents with low affect load. On the other hand, among individuals primed for selective emotional reactivity, disturbed dreaming may serve activators of previously encoded traumatic experiences and results in waking negative affective reactions, and subsequently to more frequent nightmares (Levin \& Nielsen, 2009).

Taking together, causal relations between sleep and dissociative symptoms seem to be reciprocal; however, mechanisms underpinning the effects of these two psychological phenomena to each other may differentiate. Scholars have argued that a labile sleep wake cycle is connected with dissociative symptomatology. It was contended that dream-like states arising from a labilesleep-wake cycle intrudes into waking consciousness, produces memory failures, and triggers dissociative experiences (Giesbrecht, Lynn, Lilienfeld, \& Merckelbach, 2008; Koffel \& Watson, 2009; van der Kloet, Merckelbach, et al., 2012; Watson, 2001). Levin and Nielsen (2007) proposed the concept of 'cross-state continuity' that assumes the brain areas and cognitive processes implicated in nightmare production are responsible in the pathophysiology of emotion dysregulation during the waking states. In a similar vein, the notion of 'transliminality', which denotes individual differences in 
the extent to which mentation may cross into or out of consciousness (Thalbourne \& Houran, 2000). In a longitudinal investigation, Soffer-Dudek and Shahar (2009) found that transliminality as a consciousness state was predictive of sleep-related experiences over a 3-month period.

On the other hand, dissociative symptomatology is intrusive and imaginative in nature (Boon, Steele, \& van der Hart, 2011). Contrary to dissociative phenomena, worry is mainly verbal, more realistic, less voluntary, more distressing, and of longer duration (Wells \& Morrison, 1994). Furthermore, worry is experienced primarily as negative verbal activity as opposed to imaginal (Borkovec \& Inz, 1990; Freeston, Dugas, \& Ladouceur, 1996). Accumulated evidence has lent support for the conclusion that worry as a state has been associated with left frontal cortex activation (Borkovec, Ray, \& Stöber, 1998; Carter, Johnson, \& Borkovec, 1986). Imagery seems to be no longer allowed due to excessive thought contained in worry process (Borkovec et al., 2004). Given the dualcoding theory, the verbal nature of worry limits accessibility to parallel-processed images, particularly in cases of catastrophic images in which they become less vivid and intrusive (Paivio, 1986; Stöber, 1997; Stöber, Tepperwien, \& Staak, 2000). Worry may function as an avoidance response originate from distress triggered by the cues of threat stimuli which may be in forms of fantasy or imagery. More precisely, the same avoidance mechanism can be applied to the linkage between dissociative symptoms and sleep disruption that dissociative experiences which contain intense emotionladen imagery material may probably lead to heighted worry that in turn causally implicated in sleep disturbance. The current preliminary evidence provided support for the cognitive avoidance hypothesis in sleep problems. Our results are consistent with the previous findings highlighting the predictive value of dissociative absorption on sleep-related outcomes (Fassler et al., 2006; Knox \& Lynn, 2014; Soffer-Dudek et al., 2017). Furthermore, intriguingly, dissociative amnesia was a significant determinant of poor sleep quality through pathological worry.

\section{LIMITATIONS AND CONCLUSION}

This study has several drawbacks. First, the sample of the study is relatively small limiting the generalizability of the current data. Secondly, the study was cross-sectional that using longitudinal research design the relationships between sleep-wake cycle, worry and dissociative could have been more profoundly investigated. Third, although worry is central in the theoretical elucidations concerning sleep problems, the scope of conceptualizations capturing repetitive thinking is large. A more comprehensive investigation into the relations between repetitive thoughts and sleep disturbance will be beneficial to understand etiology of sleep problems.

Despite the drawbacks of the study, the current data attested to the crucial relations between dissociative symptomatology and sleep by means of pathological worry. Trauma model is the prevailing notion considering the etiology of dissociative disorders that a more profound understanding of the relationships with sleep will contribute to further refinements regarding nontraumatic etiology of dissociative experiences (Butler, Duran, Jasiukaitis, Koopman, \& Spiegel, 1996; Lilienfeld et al., 1999; Watson, 2003). The current results may be interpreted in a way that both pathological worry and dissociative amnesia may play role in the cognitive suppression of negative content arising from stressful life events at the expense of normal sleep-wake cycle.

\section{Declaration of Conflicting Interests}

The authors declared no potential conflicts of interest with respect to the research, authorship, and/or publication of this article.

\section{Funding}

The authors received no financial support for the research, authorship, and/or publication of this article. 


\section{References}

Abdel-Khalek, A. M. (2009). The relation between insomnia and chronic fatigue among a non-clinical sample using questionnaires. Sleep and Hypnosis, 11(1), 9-17.

Abrams, M. P., Mulligan, A. D., Carleton, R. N., \& Asmundson, G. J. G. (2008). Prevalence and correlates of sleep paralysis in adults reporting childhood sexual abuse. Journal of Anxiety Disorders, 22(8), 1535-1541. doi:10.1016/j.janxdis.2008.03.007

Adan, A., Fabbri, M., Natale, V., \& Prat, G. (2006). Sleep Beliefs Scale (SBS) and circadian typology. Journal of Sleep Research, 15(2), 125-132.

Agargun, M. Y., Boysan, M., \& Hanoglu, L. (2004). Sleeping position, dream emotions, and subjective sleep quality. Sleep and Hypnosis, 6(1), 8-13.

Agargun, M. Y., Kara, H., \& Anlar, Ö. (1996). Validity and reliability of the Pittsburgh Sleep Quality Index. Turkish Journal of Psychiatry, 7(2), 107-115.

Agargun, M. Y., Kara, H., Ozer, O. A., Selvi, Y., Kiran, U., \& Kiran, S. (2003). Nightmares and dissociative experiences: The key role of childhood traumatic events. Psychiatry and Clinical Neuroscience, $57(2), \quad 139-145$. doi:10.1046/j.1440-1819.2003.01093.x

Agargun, M. Y., Kara, H., Ozer, O. A., Selvi, Y., Kiran, U., \& Ozer, B. (2003). Clinical importance of nightmare disorder in patients with dissociative disorders. Psychiatry and Clinical Neuroscience, $\quad 57(6), \quad 575-579$. doi:10.1046/j.1440-1819.2003.01169.x

American Psychiatric Association. (2013). Diagnostic and Statistical Manual of Mental Disorders, 5th Edition: DSM-5. Washington, DC: American Psychiatric Publishing.

Armour, C., Contractor, A. A., Palmieri, P. A., \& Elhai, J. D. (2014). Assessing latent level associations between PTSD and dissociative factors: Is depersonalization and derealization related to PTSD factors more so than alternative dissociative factors? Psychological Injury and Law, 7(2), 131-142. doi:10.1007/s12207-014-9196-9

Aydin, A., Selvi, Y., Besiroglu, L., Boysan, M., Atli, A., Ozdemir, O., . . Balaharoglu, R. (2013). Mood and metabolic consequences of sleep deprivation as a potential endophenotype in bipolar disorder. Journal of Affective Disorders, 150(2), 284-294. doi:10.1016/j.jad.2013.04.007

BaHammam, A., Al-Faris, E., Shaikh, S., \& Saeed, A. B. (2006). Sleep problems/habits and school performance in elementary school children. Sleep and Hypnosis, 8(1), 12-18.

Barrett, D. (1994). Dreaming as a normal model for multiple personality disorder. In S. J. Lynn \& J. W. Rhue (Eds.), Dissociation: Clinical and theoretical perspectives (pp. 123135). New York, NY: Guilford.

Barrett, D. (1995). The dream character as a prototype for the multiple personality alter. Dissociation, 8, 61-68.

Beaulieu-Prevost, D., \& Zadra, A. (2007). Absorption, psychological boundaries and attitude towards dreams as correlates of dream recall: two decades of research seen through a metaanalysis. Journal of Sleep Research, 16(1), 51-59. doi:10.1111/j.1365-2869.2007.00572.x

Blagrove, M., \& Pace-Schott, E. F. (2010). Trait and neurobiological correlates of individual differences in dream recall and dream content. International Review of Neurobiology, 92, 155-180. doi:10.1016/S0074-7742(10)92008-4

Bob, P. (2004). Dissociative processes, multiple personality, and dream functions. American Journal of Psychotherapy, 58, 139-149.
Bob, P., \& Louchakova, O. (2015). Dissociative states in dreams and brain chaos: Implications for creative awareness. Frontiers of Psychology, 6, 1353. doi:10.3389/fpsyg.2015.01353

Bonnet, M. H., \& Arand, D. L. (1995). 24-Hour metabolic rate in insomniacs and matched normal sleepers. Sleep, 18(7), 581588.

Bonnet, M. H., \& Arand, D. L. (1997a). Heart rate variability: Sleep stage, time of night, and arousal influences. Electroencephalography and Clinical Neurophysiology, 102(5), 390-396.

Bonnet, M. H., \& Arand, D. L. (1997b). Physiological activation in patients with sleep state misperception. Psychosomatic Medicine, 59(5), 533-540.

Bonnet, M. H., \& Arand, D. L. (2010). Hyperarousal and insomnia: state of the science. Sleep Medicine Review, 14(1), 9-15. doi:10.1016/j.smrv.2009.05.002

Boon, S., Steele, K., \& van der Hart, O. (2011). Coping with traumarelated dissociation: Skills training for patients and therapists. New York, NY: W. W. Norton \& Company.

Bootzin, R. R. (1972, September 2-8). A stimulus control treatment for insomnia. Paper presented at the APA 80th Annual Convention, Honolulu: HI.

Bootzin, R. R., Lack, L., \& Wright, H. (1999). Efficacy of bright light and stimulus control instructions for sleep onset insomnia. Sleep, 22(Suppl 1), 53-54.

Bootzin, R. R., \& Rider, S. P. (1997). Behavioral techniques and biofeedback for insomnia. In M. R. Pressman \& W. C. Orr (Eds.), Understanding sleep: The evaluation and treatment of sleep disorders (pp. 315-338): American Psychological Association.

Borkovec, T. D. (1982). Insomnia. Journal of Consulting and Clinical Psychology, 50(6), 880-895.

Borkovec, T. D., Alcaine, O., \& Behar, E. (2004). Avoidance theory of worry and generalized anxiety disorder. In R. G. Heimberg, C. L. Turk, \& D. S. Mennin (Eds.), Generalized anxiety disorder: Advances in research and practice (pp. 77-108). New York: NY: Guilford.

Borkovec, T. D., \& Inz, J. (1990). The nature of worry in generalized anxiety disorder: A predominance of thought activity. Behaviour Research and Therapy, 28(2), 153-158. doi:10.1016/0005-7967(90)90027-G

Borkovec, T. D., Ray, W. J., \& Stober, J. (1998). Worry: A cognitive phenomenon intimately linked to affective, physiological, and interpersonal behavioral processes. Cognitive Therapy and Research, 22(6), 561-576. doi:10.1023/A:1018790003416

Borkovec, T. D., Ray, W. J., \& Stöber, J. (1998). Worry: A cognitive phenomenon intimately linked to affective, physiological, and interpersonal behavioral processes. Cognitive Therapy and Research, 22(6), 561-576. doi:10.1023/A: 1018790003416

Borkovec, T. D., Robinson, E., Pruzinsky, T., \& DePree, J. A. (1983). Preliminary exploration of worry: Some characteristics and processes. Behaviour Research Therapy, 21(1), 9-16.

Boysan, M. (2014a). Dissociative experiences are associated with obsessive-compulsive symptoms in a non-clinical sample: A latent profile analysis. Archives of Neuropsychiatry, 51(3), 253262. doi:10.4274/npa.y6884

Boysan, M. (2014b). Dissociative experiences are associated with obsessive-compulsive symptoms in a non-clinical sample: a latent profile analysis. Noropsikiyatri Arsivi-Archives of Neuropsychiatry, 51(3), 253-262. doi:10.4274/npa.y6884 
Boysan, M. (2016a). Associations between dissociation and posttraumatic stress response. In C. R. Martin, V. R. Preedy, \& V. B. Patel (Eds.), Comprehensive guide to post-traumatic stress disorder (pp. 831-849). New York, NY: Springer.

Boysan, M. (2016b). Developmental implications of sleep. Sleep and Hypnosis, 18(2), 44-52. doi:10.5350/Sleep.Hypn. 2016.18.0108

Boysan, M., Goldsmith, R. E., Cavus, H., Kayri, M., \& Keskin, S. (2009). Relations among anxiety, depression, and dissociative symptoms: the influence of abuse subtype. Journal of Trauma and Dissociation, 10(1), 83-101. doi:10.1080/15299730802485185

Boysan, M., Güleç, M., Beşiroğlu, L., \& Kalafat, T. (2010). Psychometric properties of the Insomnia Severity Index in Turkish sample. Anatolian Journal of Psychiatry, 11, 248-252.

Boysan, M., \& Kagan, M. (2016). Associations between career decision-making difficulties, maladaptive limitedness schemas, sleep quality, and circadian preferences among Turkish college students. Sleep and Hypnosis, 18(4), 97-110. doi:10.5350/Sleep. Hypn.2016.18.0124

Boysan, M., Keskin, S., \& Besiroglu, L. (2008). Assessment of hierarchical factor structure, reliability and validity of Penn State Worry Questionnaire Turkish version. Bulletin of Clinical Psychopharmacology, 18(3), 174-182.

Boysan, M., \& Kiral, E. (2016). An investigation into the interactions between positive and negative aspects of personality, perfectionism, coping, and locus of control: A latent profile analysis. Sleep and Hypnosis, 18(2), 53-64. doi:10.5350/Sleep. Hypn.2016.18.0116

Boysan, M., Merey, Z., Kalafat, T., \& Kağan, M. (2010). Validation of a brief version of the dysfunctional beliefs and attitudes about sleep scale in Turkish sample. Procedia-Social and Behavioral Sciences, 5, 314-317. doi:10.1016/j.sbspro.2010.07.095

Braude, S. (2009). The conceptual unity of dissociation: A philosophical argument. In P. Dell \& J. O'Neil (Eds.), Dissociation and the dissociative disorders: DSM-V and beyond (pp. 27-36). New York, NY: Routledge.

Brosschot, J. F., Gerin, W., \& Thayer, J. F. (2006). The perseverative cognition hypothesis: A review of worry, prolonged stressrelated physiological activation, and health. Journal of Psychosomatic Research, 60(2), 113-124. doi:10.1016/j. jpsychores.2005.06.074

Brosschot, J. F., Piepera, S., \& Thayer, J. F. (2005). Expanding stress theory: Prolonged activation and perseverative cognition. Psychoneuroendocrinology, 30, 1043-1049.

Brown, T. A., Antony, M. M., \& Barlow, D. H. (1992). Psychometric properties of the Penn State Worry Questionnaire in a clinical anxiety disorders sample. Behaviour Research and Therapy, 30(1), 33-37.

Buhr, K., \& Dugas, M. J. (2006). Investigating the construct validity of intolerance of uncertainty and its unique relationship with worry. Journal of Anxiety Disorders, 20(2), 222-236. doi:10.1016/j.janxdis.2004.12.004

Butler, L. D., Duran, R. E., Jasiukaitis, P., Koopman, C., \& Spiegel, D. (1996). Hypnotizability and traumatic experience: A diathesisstress model of dissociative symptomatology. American Journal of Pyschiatry, 153(Suppl 7), 42-63. doi:10.1176/ajp.153.8.A42

Buysse, D. J. (2010). Overview of treatment considerations. In M. sSateia \& D. J. Buysse (Eds.), Insomnia: Diagnosis and treatment (pp. 256-259). London, UK: Informa Health Care.

Buysse, D. J., Reynolds, C. F., Monk, T. H., Berman, S. R., \& Kupfer, D. J. (1989). The Pittsburgh Sleep Quality Index: A new instrument for psychiatric practice and research. Psychiatry Research, 28(2), 193-213. doi: 10.1016/0165-1781(89)90047-4
Carlson, E. B., Putnam, F. W., Ross, C. A., Torem, M., Coons, P., Dill, D. L., . . . Braun, B. G. (1993). Validity of the Dissociative Experiences Scale in Screening for Multiple PersonalityDisorder - a Multicenter Study. American Journal of Psychiatry, 150(7), 1030-1036

Carskadon, M. A., \& Dement, W. C. (2011). Monitoring and staging human sleep. In M. H. Kryger, T. Roth, \& W. C. Dement (Eds.), Principles and practice of sleep medicine (5th Ed ed., pp. 1626). St. Louis: Elsevier Saunders.

Carter, W. R., Johnson, M. C., \& Borkovec, T. D. (1986). Worry: An electrocortical analysis. Advances in Behaviour Research and Therapy, 8(4), 193-204. doi:10.1016/0146-6402(86)90004-4

Chee, M. W., \& Chuah, L. Y. (2008). Functional neuroimaging insights into how sleep and sleep deprivation affect memory and cognition. Current Opinion in Neurology, 21(4), 417-423. doi:10.1097/WCO.0b013e3283052cf7

Chee, M. W., \& Chuah, Y. M. (2007). Functional neuroimaging and behavioral correlates of capacity decline in visual short-term memory after sleep deprivation. Proceedings of the National Academy of Sciences of the United States, 104(22), 94879492. doi:10.1073/pnas.0610712104

Cheung, V. K. L. (2012). An exploratory study on the relationship between dissociation in waking life and negative contents in dreams. International Journal of Dream Research, 5(1), 17-22.

Chiang, Y. C., Arendt, S., Zheng, T., \& Hanisch, K. (2014). The effects of sleep on academic performance and job performance. College Student Journal, 48(1), 72-87.

Conway, M., Csank, P. A., Holm, S. L., \& Blake, C. K. (2000). On assessing individual differences in rumination on sadness. Journal of Personality Assessment, 75(3), 404-425. doi:10.1207/S15327752JPA7503_04

Conway, M., Mendelson, M., Giannopoulos, C., Csank, P. A., \& Holm, S. L. (2004). Childhood and adult sexual abuse, rumination on sadness, and dysphoria. Child Abuse and Neglect, 28(4), 393-410. doi:10.1016/j.chiabu.2003.05.004

Coutanche, M. N., \& Thompson-Schill, S. L. (2012). Reversal without remapping: What we can (and cannot) conclude about learned associations from training-induced behavior changes. Perspectves on Psychological Science, 7(2), 118-134. doi:10.1177/1745691611434211

Crick, F., \& Mitchison, G. (1995). REM sleep and neural nets. Behavioural Brain Research, 69(1-2), 147-155. doi:10.1016/0166-4328(95)00006-F

Dar, K. A., Iqbal, N., \& Mushtaq, A. (2017). Intolerance of uncertainty, depression, and anxiety: Examining the indirect and moderating effects of worry. Asian Journal of Psychiatry, 29, 129-133. doi:10.1016/j.ajp.2017.04.017

De Havas, J. A., Parimal, S., Soon, C. S., \& Chee, M. W. (2012). Sleep deprivation reduces default mode network connectivity and anti-correlation during rest and task performance. Neuroimage, 59(2), 1745-1751. doi:10.1016/j. neuroimage.2011.08.026

Desseilles, M., Dang-Vu, T. T., Sterpenich, V., \& Schwartz, S. (2011). Cognitive and emotional processes during dreaming: a neuroimaging view. Consciousness and Cognition, 20(4), 9981008. doi:10.1016/j.concog.2010.10.005

Dugas, M. J., Freeston, M. H., \& Ladouceur, R. (1997). Intolerance of uncertainty and problem orientation in worry. Cognitive Therapy and Research, 21(6), 593-606.

Dugas, M. J., Gosselin, P., \& Ladouceur, R. (2001). Intolerance of uncertainty and worry: Investigating specificity in a nonclinical sample. Cognitive Therapy and Research, 25(5), 551-558. doi:10.1023/A:100555341 
Dugas, M. J., Schwartz, A., \& Francis, K. (2004). Brief report: Intolerance of uncertainty, worry, and depression. Cognitive Therapy and Research, 28(6), 835-842.

Engle-Friedman, M., \& Riela, S. (2004). Self-imposed sleep loss, sleepiness, effort and performance. Sleep and Hypnosis, 6 , 155-162.

Erdur-Baker, O., \& Bugay, A. (2012). The Turkish version of the Ruminative Response Scale: an examination of its reliability and validity. The International Journal of Educational and Psychological Assessment, 10(2), 1-16.

Espie, C. A. (2002). Insomnia: Conceptual issues in the development, persistence, and treatment of sleep disorder in adults. Annual Review of Psychology, 53, 215-243. doi:10.1146/ annurev.psych.53.100901.135243

Espie, C. A., Inglis, S. J., Harvey, L., \& Tessier, S. (2000). Insomniacs' attributions. psychometric properties of the Dysfunctional Beliefs and Attitudes about Sleep Scale and the Sleep Disturbance Questionnaire. Journal of Psychosomatic Research, 48(2), 141-148. doi:10.1016/S0022-3999(99)000902

Fairholme, C. P., \& Manber, R. (2014). Safety behaviors and sleep effort predict sleep disturbance and fatigue in an outpatient sample with anxiety and depressive disorders. Journal of Psychosomatic Research, 76(3), 233-236. doi:10.1016/j. jpsychores.2014.01.001

Fassler, O., Knox, J., \& Lynn, S. J. (2006). The lowa Sleep Experiences Survey: Hypnotizability, absorption, and dissociation. Personality and Individual Differences, 41(4), 675684. doi:10.1016/j.paid.2006.03.007

Feldman, G. C., Joormann, J., \& Johnson, S. L. (2008). Responses to positive affect: A self-report measure of rumination and dampening. Cognitive Therapy and Research, 32(4), 507-525. doi:10.1007/s10608-006-9083-0

Freeston, M. H., Dugas, M. J., \& Ladouceur, R. (1996). Thoughts, images, worry, and anxiety. Cognitive Therapy and Research, 20(3), 265-273. doi:10.1007/BF02229237

Gendron, L., Blais, F. C., \& Morin, C. M. (1998). Cognitive activity among insomniac patients. Sleep, 21, 130.

Giesbrecht, T., Jongen, E. M. M., Smulders, F. T. Y., \& Merckelbach, H. (2006). Dissociation, resting EEG, and subjective sleep experiences in undergraduates. Journal of Nervous and Mental Disease, 194(5), 362-368. doi:10.1097/01. nmd.0000217821.18908.bf

Giesbrecht, T., Lynn, S. J., Lilienfeld, S. O., \& Merckelbach, H. (2008). Cognitive processes in dissociation: An analysis of core theoretical assumptions. Psychological Bulletin, 134(5), 617647. doi:10.1037/0033-2909.134.5.617

Giesbrecht, T., \& Merckelbach, H. (2004). Subjective sleep experiences are related to dissociation. Personality and Individual Differences, 37, 1341-1345.

Giesbrecht, T., \& Merckelbach, H. (2006). Dreaming to reduce fantasy?: Fantasy proneness, dissociation, and subjective sleep experiences. Personality and Individual Differences, 41(4), 697706. doi:10.1016/j.paid.2006.02.015

Giesbrecht, T., Smeets, T., Leppink, J., Jelicic, M., \& Merckelbach, H. (2007). Acute dissociation after 1 night of sleep loss. Journal of Abnormal Psychology, 116(3), 599-606. doi:10.1037/0021843X.116.3.599

Ginzburg, K., Koopman, C., Butler, L. D., Palesh, O., Kraemer, H. C., Classen, C. C., \& Spiegel, D. (2006). Evidence for a dissociative subtype of post-traumatic stress disorder among help-seeking childhood sexual abuse survivors. Journal of Trauma \& Dissociation, 7(2), 7-27.
Goldstein, A. J., \& Chambless, D. L. (1978). A reanalysis of agoraphobia. Behavior Therapy, 9(1), 47-59. doi:10.1016/ S0005-7894(78)80053-7

Gulec, M., Selvi, Y., Boysan, M., Aydin, A., Besiroglu, L., \& Agargun, M. Y. (2011). Ongoing or re-emerging subjective insomnia symptoms after full/partial remission or recovery of major depressive disorder mainly with the selective serotonin reuptake inhibitors and risk of relapse or recurrence: a 52week follow-up study. Journal of Affective Disorders, 134(1-3), 257-265. doi:10.1016/j.jad.2011.05.056

Gulec, M., Selvi, Y., Boysan, M., Aydin, A., Oral, E., \& Aydin, E. F. (2013). Chronotype effects on general well-being and psychopathology levels in healthy young adults. Biological Rhythm Research, 44(3), 457-468. doi:10.1080/09291016.2012 .704795

Harvey, A. G. (2000). Pre-sleep cognitive activity: A comparison of sleep-onset insomniacs and good sleepers. British Journal of Clinical Psychology, 39(3), 275-286. doi:10.1348/014466500163284

Harvey, A. G. (2002). A cognitive model of insomnia. Behaviour Research and Therapy, 40(8), 869-893.

Harvey, A. G. (2006). What about patients who can't sleep? Case formulation for insomnia. In N. Tarrier (Ed.), Case formulation in cognitive behavioral therapy: The treatment of challenging and complex cases (pp. 293-311). New York: NY: Routledge.

Harvey, A. G., \& Greenall, E. (2003). Catastrophic worry in primary insomnia. Journal of Behavior Therapy and Experimental Psychiatry, 34(1), 11-23. doi:10.1016/S0005-7916(03)00003-X

Harvey, A. G., \& Tang, N. K. (2012). (Mis)perception of sleep in insomnia: A puzzle and a resolution. Psychological Bulletin, 138(1), 77-101. doi:10.1037/a0025730

Harvey, A. G., Tang, N. K., \& Browning, L. (2005). Cognitive approaches to insomnia. Clinical Psychology Review, 25(5), 593-611. doi:10.1016/j.cpr.2005.04.005

Harvey, A. G., Watkins, E., Mansell, W., \& Shafran, R. (2004). Cognitive behavioural processes across psychological disorders. Oxford, United Kingdom: Oxford University Press.

Hiller, R. M., Johnston, A., Dohnt, H., Lovato, N., \& Gradisar, M. (2015). Assessing cognitive processes related to insomnia: A review and measurement guide for Harvey's cognitive model for the maintenance of insomnia. Sleep Medicine Review, 23, 46-53. doi:10.1016/j.smrv.2014.11.006

Holmes, E. A., Brown, R. J., Mansell, W., Fearon, R. P., Hunter, E. C. M., Frasquilho, F., \& Oakley, D. A. (2005). Are there two qualitatively distinct forms of dissociation? A review and some clinical implications. Clinical Psychology Review, 25(1), 1-23. doi:10.1016/j.cpr.2004.08.006

Hood, H. K., Carney, C. E., \& Harris, A. L. (2011). Rethinking safety behaviors in insomnia: examining the perceived utility of sleeprelated safety behaviors. Behavior Therapy, 42(4), 644-654. doi:10.1016/j.beth.2011.02.004

Hunter, E. C., Phillips, M. L., Chalder, T., Sierra, M., \& David, A. S. (2003). Depersonalisation disorder: a cognitive-behavioural conceptualisation. Behavior Research and Therapy, 41(12), 1451-1467. doi:10.1016/S0005-7967(03)00066-4

Johnson, S. L., McKenzie, G., \& McMurrich, S. (2008). Ruminative responses to negative and positive affect among students diagnosed with bipolar disorder and major depressive disorder. Cognitive Therapy and Research, 32(5), 702-713. doi:10.1007/ s10608-007-9158-6

Kadak, M. T., Nasiroglu, S., Boysan, M., \& Aydin, A. (2013). Risk factors predicting posttraumatic stress reactions in adolescents after 2011 Van earthquake. Comprehensive Psychiatry, 54(7), 982-990. doi:10.1016/j.comppsych.2013.04.003 
Kağan, M. (2011). Frost Çok Boyutlu Mükemmeliyetçilik Ölçeği'nin Türkçe Formunun Psikometrik Özellikleri. Anadolu Psikiyatri Dergisi, 12(3), 192-197.

Kales, A., Caldwell, A. B., Preston, T. A., Healey, S., \& Kales, J. D. (1976). Personality patterns in insomnia: Theoretical implications. Archives of General Psychiatry, 33(9), 1128-1124. doi:10.1001/archpsyc.1976.01770090118013

Kashdan, T. B., \& Roberts, J. E. (2007). Social anxiety, depressive symptoms, and post-event rumination: affective consequences and social contextual influences. Journal of Anxiety Disorders, 21(3), 284-301. doi:10.1016/j.janxdis.2006.05.009

Kelly, W. E. (2017). The Nightmare Proneness Scale: A proposed measure for the tendency to experience nightmares. Sleep and Hypnosis. doi:10.5350/Sleep.Hypn.2017.19.0143

Knox, J., \& Lynn, S. J. (2014). Sleep experiences, dissociation, imaginal experiences, and schizotypy: The role of context. Consciousness and Cognition, 23, 22-31. doi:10.1016/j. concog.2013.10.007

Knutson, K. L., Spiegel, K., Penev, P., \& Van Cauter, E. (2007). The metabolic consequences of sleep deprivation. Sleep Medicine Review, 11(3), 163-178. doi:10.1016/j.smrv.2007.01.002

Koffel, E., \& Watson, D. (2009). Unusual sleep experiences, dissociation, and schizotypy: Evidence for a common domain. Clinical Psychology Review, 29(6), 548-559. doi:10.1016/j. cpr.2009.06.004

Kuisk, L. A., Bertelson, A. D., \& Walsh, J. K. (1989). Presleep cognitive hyperarousal and affect as factors in objective and subjective insomnia. Perceptual and Motor Skills, 69, 12191225. doi:10.2466/pms.1989.69.3f.1219

La Via, M. C., \& Brewerton, T. D. (1996). Cataplexy and the switch process of multiple personality disorder. Psychiatry Research, 63(2), 231-232.

Laakso, J., Herrala, J., M kinen, R., Rantala, T., Lahdensuo, A., Ojanen, M., \& Hasan, J. (1999). Impairment of quality of life and daytime performance in mild form of sleep related breathing disorder. Sleep and Hypnosis, 1(3), 163-172.

Ladouceur, R., Gosselin, P., \& Dugas, M. J. (2000). Experimental manipulation of intolerance of uncertainty: a study of a theoretical model of worry. Behaviour Research and Therapy, 38(9), 933-941. doi:10.1016/S0005-7967(99)00133-3

Lahl, O., \& Pietrowsky, R. (2006). Does the" sleep effect" on memory depend on sleep or on night time? Sleep and Hypnosis, 8(2), 61-70.

Lahl, O., \& Pietrowsky, R. (2007). The long range effect of sleep on episodic memory. Sleep and Hypnosis, 9(1), 24-29.

Lanius, R. A. (2015). Trauma-related dissociation and altered states of consciousness: A call for clinical, treatment, and neuroscience research. European Journal of Psychotraumatology, 6, 27905. doi:10.3402/ejpt.v6.27905

Lanius, R. A., Bluhm, R. L., Coupland, N. J., Hegadoren, K. M., Rowe, B., Theberge, J., . . Brimson, M. (2010). Default mode network connectivity as a predictor of post-traumatic stress disorder symptom severity in acutely traumatized subjects. Acta Psychiatrica Scandinavica, 121(1), 33-40. doi:10.1111/j.1600-0447.2009.01391.x

Levin, R., Fireman, G., \& Rackley, C. (2003). Personality and dream recall frequency: Still further negative findings. Dreaming, 13(3), 155-162. doi:10.1023/A:1025321428651

Levin, R., \& Nielsen, T. (2009). Nightmares, bad dreams, and emotion dysregulation: A review and new neurocognitive model of dreaming. Current Directions in Psychological Science, 18(2), 84-88.
Levin, R., \& Nielsen, T. A. (2007). Disturbed dreaming, posttraumatic stress disorder, and affect distress: A review and neurocognitive model. Psychological Bulletin, 133(3), 482-528. doi:10.1037/0033-2909.133.3.482

Levin, R., \& Young, H. (2002). The relation of waking fantasy to dreaming. Imagination, Cognition and Personality, 21(3), 201219.

Lilienfeld, S. O., Lynn, S. J., Kirsch, I., Chaves, J. F., Sarbin, T. R., Ganaway, G. K., \& Powell, R. A. (1999). Dissociative identity disorder and the sociocognitive model: Recalling the lessons of the past. Psychological Bulletin, 125(5), 507-523.

Lim, J., \& Dinges, D. F. (2008). Sleep deprivation and vigilant attention. Annals of the New York Academy of Sciences, 1129, 305-322. doi:10.1196/annals.1417.002

Llewellyn, S. (2013). Such stuff as dreams are made on? Elaborative encoding, the ancient art of memory, and the hippocampus. Behavioral and Brain Sciences, 36(6), 589-607. doi:10.1017/ S0140525X12003135

Lundh, L. G. (2011). Insomnia. In M. L. McCracken (Ed.), Mindfulness and acceptance in behavioral medicine: Current theory and practice (pp. 131-158). Oakland, CA: New Harbinger Publications.

Lundh, L. G., \& Broman, J. E. (2000). Insomnia as an interaction between sleep-interfering and sleep-interpreting processes. Journal of Psychosomatic Research, 49(5), 299-310.

Mahowald, M. W., \& Schenck, C. H. (2001). Evolving concepts of human state dissociation. Archives Italiennes de Biologie, 139, 269-300.

Mandel, D. R. (2003). Counterfactuals, emotions, and context. Cognition \& Emotion, 17, 139-159.

Marques, D. R., Allen Gomes, A., Clemente, V., Santos, J. M., \& Castelo-Branco, M. (2015). Hyperarousal and failure to inhibit wakefulness in primary insomnia:"Birds of a feather"? Sleep and Biological Rhythms, 13(3), 219-228. doi:10.1111/sbr.12115

Martikainen, K., Partinen, M., Hasan, J., Laippala, P., Urponen, H., \& Vuorii, I. (2001). The problem of long-term insomnia: a 5-year follow-up study in a middle-aged population. Sleep and Hypnosis, 3(3), 97-105.

Martin, L. L., Shrira, I., \& Startup, H. M. (2004). Rumination as a function of goal progress, stop rules, and cerebral lateralization. In C. Papageorgiou \& A. Wells (Eds.), Depressive rumination: Nature, theory and treatment (pp. 153-175): Wiley.

Martin, L. L., \& Tesser, A. (1996). Some ruminative thoughts. In R. S. Wyer (Ed.), Ruminative thoughts: Advances in social cognition (Vol. 9, pp. 1-47). Hillsdale, NJ: Erlbaum.

Matos, M. G., Gaspar, T., Tomé, G., \& Paiva, T. (2016). Sleep variability and fatigue in adolescents: Associations with schoolrelated features. International Journal of Psychology, 51(5), 323-331.

McNally, R. J., \& Clancy, S. A. (2005a). Sleep paralysis in adults reporting repressed, recovered, or continuous memories of childhood sexual abuse. Journal of Anxiety Disorders, 19(5), 595-602.

McNally, R. J., \& Clancy, S. A. (2005b). Sleep paralysis, sexual abuse, and space alien abduction. Transcultural Psychiatry, 42(1), 113-122.

Meyer, T. J., Miller, M. L., Metzger, R. L., \& Borkovec, T. D. (1990). Development and validation of the Penn State Worry Questionnaire. Behaviour Research and Therapy, 28(6), 487495. doi:10.1016/0005-7967(90)90135-6

Minkel, J. D., McNealy, K., Gianaros, P. J., Drabant, E. M., Gross, J. J., Manuck, S. B., \& Hariri, A. R. (2012). Sleep quality and neural circuit function supporting emotion regulation. Biology of Mood and Anxiety Disorders, 2, 22. doi:10.1186/2045-5380-2-22 
Morin, C. M. (1993). Insomnia: Psychological assessment and management. New York: NY: Guildford.

Morin, C. M., Vallieres, A., \& Ivers, H. (2007). Dysfunctional beliefs and attitudes about sleep (DBAS): validation of a brief version (DBAS-16). Sleep, 30(11), 1547-1554.

Mowrer, O. H. (1947). On the dual nature of learning: A reinterpretation of "conditioning" and "problem-solving. Harvard Educational Review, 17, 102-148.

Nicassio, P. M., Mendlowitz, D. R., Fussell, J. J., \& Petras, L. (1985). The phenomenology of the pre-sleep state: the development of the pre-sleep arousal scale. Behaviour Research and Therapy, 23(3), 263-271. doi:10.1016/0005-7967(85)90004-X

Nicholson, A. A., Densmore, M., Frewen, P. A., Theberge, J., Neufeld, R. W., McKinnon, M. C., \& Lanius, R. A. (2015). The dissociative subtype of posttraumatic stress disorder: Unique resting-state functional connectivity of basolateral and centromedial amygdala complexes. Neuropsychopharmacology, 40(10), 2317-2326. doi:10.1038/ npp.2015.79

Nielsen, T., \& Levin, R. (2007). Nightmares: A new neurocognitive model. Sleep Medicine Review, 11(4), 295-310. doi:10.1016/j. smrv.2007.03.004

Nilsson, J. P., Soderstrom, M., Karlsson, A. U., Lekander, M., Akerstedt, T., Lindroth, N. E., \& Axelsson, J. (2005). Less effective executive functioning after one night's sleep deprivation. Journal of Sleep Research, 14(1), 1-6. doi:10.1111/j.1365-2869.2005.00442.x

Nolen-Hoeksema, S. (1991). Responses to depression and their effects on the duration of depressive episodes. Journal of Abnormal Psychology, 100(4), 569-582. doi:10.1037/0021843X.100.4.569

Nolen-Hoeksema, S. (2004). The response styles theory. In C. Papageorgiou \& A. Wells (Eds.), Depressive rumination (pp. 107-124). Chichester, United Kingdom: Wiley.

Norem, J. K., \& Cantor, N. (1986a). Anticipatory and post hoc cushioning strategies: Optimism and defensive pessimism in "risky" situations. Cognitive Therapy and Research, 10(3), 347362.

Norem, J. K., \& Cantor, N. (1986b). Defensive pessimism: Harnessing anxiety as motivation. Journal of Personality and Social Psychology, 51, 1208-1217.

Norem, J. K., \& Chang, E. C. (2002). The positive psychology of negative thinking. Journal of Clinical Psychology, 58, 9931001.

Oathes, D. J., \& Ray, W. J. (2008). Dissociative tendencies and facilitated emotional processing. Emotion, 8(5), 653-661. doi:10.1037/a0013442

Olatunji, B. O., Broman-Fulks, J. J., Bergman, S. M., Green, B. A., \& Zlomke, K. R. (2010). A taxometric investigation of the latent structure of worry: dimensionality and associations with depression, anxiety, and stress. Behavior Therapy, 41(2), 212228. doi:10.1016/j.beth.2009.03.001

Ong, J. C., Manber, R., Segal, Z., Xia, Y., Shapiro, S., \& Wyatt, J. K. (2014). A randomized controlled trial of mindfulness meditation for chronic insomnia. Sleep, 37(9), 1553-1563. doi:10.5665/ sleep.4010

Ong, J. C., Ulmer, C. S., \& Manber, R. (2012). Improving sleep with mindfulness and acceptance: A metacognitive model of insomnia. Behaviour Research and Therapy, 50(11), 651-660. doi:10.1016/j.brat.2012.08.001

Özgülük, B., Baker, Ö. E., \& Bugay, A. (2012). Turkish Version of Children's Response Styles Questionnaire. European Journal of Psychological Assessment, 28, 154-160. doi:10.1027/10155759/a000104
Paiva, T., Gaspar, T., \& Matos, M. G. (2015). Sleep deprivation in adolescents: correlations with health complaints and healthrelated quality of life. Sleep Medicine, 16(4), 521-527. doi:10.1016/j.sleep.2014.10.010

Paivio, A. (1986). Mental representations: A dual coding approach. New York, NY: Oxford University Press.

Perlis, M. L., Giles, D. E., Mendelson, W. B., Bootzin, R. R., \& Wyatt, J. K. (1997). Psychophysiological insomnia: the behavioural model and a neurocognitive perspective. Journal of Sleep Research, 6(3), 179-188.

Perlis, M. L., Merica, H., Smith, M. T., \& Giles, D. E. (2001). Beta EEG activity and insomnia. Sleep Medicine Review, 5(5), 363-374. doi:10.1053/smrv.2001.0151

Pham, L. B., \& Taylor, S. E. (1999). From thought to action: Effects of process- versus outcome-based mental simulations on performance. Personality and Social Psychology Bulletin, 25(2), 250-260. doi:10.1177/0146167299025002010

Pieper, S., \& Brosschot, J. F. (2005). Prolonged stress-related cardiovascular activation: Is there any? Annals of Behavioral Medicine, 30, 91-103. doi:10.1207/s15324796abm3002_1

Putnam, F. W. (1997). Dissociation in children and adolescents. A developmental perspective. New York: Guilford Press.

Putnam, F. W., Carlson, E. B., Ross, C. A., Anderson, G., Clark, P., Torem, M., ... Braun, B. G. (1996). Patterns of dissociation in clinical and nonclinical samples. Journal of Nervous and Mental Disease, 184(11), 673-679. doi: 10.1097/00005053199611000-00004

Rauschenberger, S. L., \& Lynn, S. J. (1995). Fantasy proneness, DSM-III-R axis I psychopathology, and dissociation. Journal of Abnormal Psychology, 104(2), 373-380.

Reiss, S., Peterson, R. A., Gursky, D. M., \& McNally, R. J. (1986). Anxiety sensitivity, anxiety frequency and the prediction of fearfulness. Behaviour Research and Therapy, 24(1), 1-8. doi:10.1016/0005-7967(86)90143-9

Rek, S., Sheaves, B., \& Freeman, D. (2017). Nightmares in the general population: identifying potential causal factors. Social Psychiatry and Psychiatric Epidemiology. doi:10.1007/s00127017-1408-7

Riemann, D., Spiegelhalder, K., Feige, B., Voderholzer, U., Berger, M., Perlis, M., \& Nissen, C. (2010). The hyperarousal model of insomnia: a review of the concept and its evidence. Sleep Medicine Review, 14(1), 19-31. doi:10.1016/j. smrv.2009.04.002

Roese, N. J. (1994). The functional basis of counterfactual thinking. Journal of Personality and Social Psychology, 66 $805-818$.

Roese, N. J. (1997). Counterfactual thinking. Psychological Bulletin, 121, 133-148.

Roese, N. J., \& Olson, J. M. (1993). The structure of counterfactual thought. Personality and Social Psychology Bulletin, 19, 312319.

Ross, C. A., Ellason, J. W., \& Anderson, G. (1995). A factor analysis of the Dissociative Experiences Scale (DES) in dissociative identity disorder. Dissociation, 8(1), 229-235.

Ross, C. A., Joshi, S., \& Currie, R. (1991). Dissociative experiences in the general population: A factor analysis. Hospital and Community Psychiatry, 42, 297-301.

Ruscio, A. M., Borkovec, T. D., \& Ruscio, J. (2001). A taxometric investigation of the latent structure of worry. Journal of Abnormal Psychology, 110(3), 413-422. doi:10.1037/0021843X.110.3.413

Sanders, B., \& Green, J. A. (1994). The factor structure of the dissociative experiences scale in college students. Dissociation, 7. 23-27. 
Saper, C. B., Scammell, T. E., \& Lu, J. (2005). Hypothalamic regulation of sleep and circadian rhythms. Nature, 437(7063), 1257-1263. doi:10.1038/nature04284

Schenck, C. H., Milner, D. M., Hurwitz, T. D., \& Bundlie, S. R. (1989). Dissociative disorders presenting as somnambulism: Polysomnographic, video and clinical documentation (8 cases). Dissociation, 2(4), 194-204.

Schichl, M., Ziberi, M., Lahl, O., \& Pietrowsky, R. (2011). The influence of midday naps and relaxation-hypnosis on declarative and procedural memory performance. Sleep and Hypnosis, 13(1-2), 7-14.

Schredl, M. (2000). Dreams and dreaming: The effect of dreams on waking life. Sleep and Hypnosis, 2(3), 120-124.

Schredl, M. (2003). Continuity between waking and dreaming: A proposal for a mathematical model. Sleep and Hypnosis, 5(1), 26-39.

Schredl, M. (2006). Factors affecting the continuity between waking and dreaming: Emotional intensity and emotional tone of the waking-life event. Sleep and Hypnosis, 8(1), 1-5.

Schredl, M. (2009). Effect of dreams on daytime mood: The effects of gender and personality. Sleep and Hypnosis, 11, 5157.

Schredl, M., Jochum, S., \& Souguenet, S. (1997). Dream recall, visual memory, and absorption in imaginings. Personality and Individual Differences, 22(2), 291-292.

Selvi, Y., Aydin, A., Boysan, M., Atli, A., Agargun, M. Y., \& Besiroglu, L. (2010). Associations between chronotype, sleep quality, suicidality, and depressive symptoms in patients with major depression and healthy controls. Chronobiology International, 27(9-10), 1813-1828. doi:10.3109/07420528.2010.516380

Selvi, Y., Besiroglu, L., Aydin, A., Gulec, M., Atli, A., Boysan, M., \& Celik, C. (2012). Relations between childhood traumatic experiences, dissociation, and cognitive models in obsessive compulsive disorder. International Journal of Psychiatry in Clinical Practice, 16(1), 53-59. doi:10.3109/13651501.2011.6174 58

Selvi, Y., Kandeger, A., Boysan, M., Akbaba, N., Sayin, A. A., Tekinarslan, E., . . Sar, V. (2017). The effects of individual biological rhythm differences on sleep quality, daytime sleepiness, and dissociative experiences. Psychiatry Research, 256, 243-248. doi:j.psychres.2017.06.059

Selvi, Y., Kilic, S., Aydin, A., \& Guzel Ozdemir, P. (2015). The effects of sleep deprivation on dissociation and profiles of mood, and its association with biochemical changes. Archives of Neuropsychiatry, 52(1), 83-88. doi:10.5152/npa.2015.7116

Semiz, U. B., Basoglu, C., Ebrinc, S., \& Cetin, M. (2008). Nightmare disorder, dream anxiety, and subjective sleep quality in patients with borderline personality disorder. Psychiatry and Clinical Neurosciences, $62(1), \quad 48-55$. doi:10.1111/j.1440-1819.2007.01789.x

Sibrava, N. J., \& Borkovec, T. D. (2006). The cognitive avoidance theory of worry. In G. C. Davey \& A. Wells (Eds.), Worry and its psychological disorders: Theory, assessment and treatment (pp. 239-256). New York, NY: Wiley.

Siegel, J. M. (2005a). Clues to the functions of mammalian sleep. Nature, 437(7063), 1264-1271. doi:10.1038/nature04285

Siegel, J. M. (2005b). Functional implications of sleep development. PLoS Biology, 3(5), e178. doi:10.1371/journal. pbio.0030178

Sierra, M., \& Berrios, G. E. (2000). The Cambridge Depersonalization Scale: a new instrument for the measurement of depersonalization. Psychiatry Research, 93(2), 153-164. doi:10.1016/S0165-1781(00)00100-1
Simor, P., Csóka, S., \& Bódizs, R. (2010). Nightmares and bad dreams in patients with borderline personality disorder: Fantasy as a coping skill? European Journal of Psychiatry, 24(1), 28-37.

Smallwood, J., Fitzgerald, A., Miles, L. K., \& Phillips, L. H. (2009). Shifting moods, wandering minds: negative moods lead the mind to wander. Emotion, 9(2), 271-276. doi:10.1037/ a0014855

Smallwood, J., O'Connor, R. C., Sudbery, M. V., \& Obonsawin, M. (2007). Mind-wandering and dysphoria. Cognition and Emotion, 21(4), 816-842.

Smith, M. T., Perlis, M. L., Park, A., Smith, M. S., Pennington, J., Giles, D. E., \& Buysse, D. J. (2002). Comparative meta-analysis of pharmacotherapy and behavior therapy for persistent insomnia. American Journal of Psychiatry, 159(1), 5-11. doi:10.1176/appi.ajp.159.1.5

Soffer-Dudek, N., Lassri, D., Soffer-Dudek, N., \& Shahar, G. (2015). Dissociative absorption: An empirically unique, clinically relevant, dissociative factor. Conscious and Cognition, 36, 338-351. doi:10.1016/j.concog.2015.07.013

Soffer-Dudek, N., \& Shahar, G. (2009). What are sleep-related experiences? Associations with transliminality, psychological distress, and life stress. Consciousness and Cognition, 18(4), 891-904. doi:10.1016/j.concog.2008.07.007

Soffer-Dudek, N., \& Shahar, G. (2011). Daily stress interacts with trait dissociation to predict sleep-related experiences in young adults. Journal of Abnormal Psychology, 120(3), 719-729. doi:10.1037/a0022941

Soffer-Dudek, N., Shelef, L., Oz, I., Levkovsky, A., Erlich, I., \& Gordon, S. (2017). Absorbed in sleep: Dissociative absorption as a predictor of sleepiness following sleep deprivation in two high-functioning samples. Consciousness and Cognition, 48, 161-170. doi:10.1016/j.concog.2016.11.009

Sonkur, A., Boysan, M., \& Kadak, M. T. (2016). A psychometric investigation of the Turkish version of the Children's Response Style Scale (CRSS) using structural mediational analysis approach. Sleep and Hypnosis, 19(2), 38-53. doi:10.5350/ Sleep.Hypn.2016.18.0119

Spencer, S. M., \& Norem, J. K. (1996). Reflection and distraction: Defensive pessimism, strategic optimism, and performance. Personality and Social Psychology Bulletin, 22, 354-365.

Spielman, A. J., Caruso, L. S., \& Glovinsky, P. B. (1987). A behavioral perspective on insomnia treatment. Psychiatric Clinics of North America, 10(4), 541-553.

Stockdale, G. D., Gridley, B. E., Balogh, D. W., \& Holtgraves, T. (2002). Confirmatory factor analysis of single- and multiplefactor competing models of the dissociative experiences scale in a nonclinical sample. Assessment, 9, 94-106.

Stöber, J. (1997). Worry, problem elaboration and suppression of imagery: The role of concreteness. Behaviour Research and Therapy, 36(7-8), 751-756.

Stöber, J., Tepperwien, S., \& Staak, M. (2000). Worrying leads to reduced concreteness of problem elaborations: Evidence for the avoidance theory of worry. Anxiety, Stress \& Coping, 13(3), 217-227.

Suszek, H., \& Kopera, M. (2005). Altered states of consciousness, dissociation, and dream recall. Perceptual and Motor Skills, 100(1), 176-178. doi:10.2466/pms.100.1.176-178

Tang, N. K., Anne Schmidt, D., \& Harvey, A. G. (2007). Sleeping with the enemy: Clock monitoring in the maintenance of insomnia. Journal of Behavior Therapy and Experimental Psychiatry, 38(1), 40-55. doi:10.1016/j.jbtep.2005.07.004

Taylor, S. (2014). Anxiety sensitivity: Theory, research, and treatment of the fear of anxiety. New York, NY: Routledge. 
Taylor, S. E., Pham, L. B., Rivkin, I. D., \& Armor, D. A. (1998). Harnessing the imagination: Mental simulation, self-regulation, and coping. American Psychologist, 54(4). doi:10.1037/0003066X.53.4.429

Taylor, S. E., \& Schneider, S. K. (1989). Coping and the simulation of events. Social Cognition, 7(Special issue: Stress, coping, and social cognition), 174-194. doi:10.1521/soco.1989.7.2.174

Thalbourne, M. A., \& Houran, J. (2000). Transliminality, the Mental Experience Inventory and tolerance of ambiguity. Personality and Individual Differences, 28(5), 853-863.

Tomasi, D., Wang, R. L., Telang, F., Boronikolas, V., Jayne, M. C., Wang, G. J., ... Volkow, N. D. (2009). Impairment of attentional networks after 1 night of sleep deprivation. Cerebral Cortex, 19(1), 233-240. doi:10.1093/cercor/bhn073

Trapnell, P. D., \& Campbell, J. D. (1999). Private self-consciousness and the five-factor model of personality: distinguishing rumination from reflection. Journal of Personality and Social Psychology, 76(2), 284-304.

Van der Hart, O., \& Dorahy, M. (2009). History of the concept of dissociation. In P. Dell \& J. O'Neil (Eds.), Dissociation and the dissociative disorders: DSM-V and beyond (pp. 3-26). New York,NY: Routledge.

Van Der Kloet, D., Giesbrecht, T., Franck, E., Van Gastel, A., De Volder, I., Van Den Eede, F., ... Merckelbach, H. (2013). Dissociative symptoms and sleep parameters: An all-night polysomnography study in patients with insomnia. Comprehensive Psychiatry, 54(6), 658-664. doi:10.1016/j. comppsych.2012.12.025

van der Kloet, D., Giesbrecht, T., Lynn, S. J., Merckelbach, H., \& de Zutter, A. (2012). Sleep normalization and decrease in dissociative experiences: evaluation in an inpatient sample. Journal of Abnormal Psychology, 121(1), 140-150. doi:10.1037/ a0024781

Van der Kloet, D., Giesbrecht, T., \& Merckelbach, H. (2011). Slaperigheid voorspelt dissociatieve symptomen: een veldstudie [Sleepiness predicts dissociative symptoms: a field study]. Tijdschrift voor Psychiatrie [Journal of Psychiatry], 53, 757-763.

van der Kloet, D., Merckelbach, H., Giesbrecht, T., \& Lynn, S. J. (2012). Fragmented sleep, fragmented mind: The role of sleep in dissociative symptoms. Perspectives in Psychological Sciences, 7(2), 159-175. doi:10.1177/1745691612437597

Van Egeren, L., Haynes, S. N., Franzen, M., \& Hamilton, J. (1983). Presleep cognitions and attributions in sleep-onset insomnia. Journal of Behavior Medicine, 6(2), 217-232. doi:10.1007/ BF00845382

van Heugten-van der Kloet, D., Giesbrecht, T., \& Merckelbach, H. (2015). Sleep loss increases dissociation and affects memory for emotional stimuli. Journal of Behavior Therapy and Experimental Psychiatry, 47, 9-17. doi:10.1016/j. jbtep.2014.11.002

van Heugten-van der Kloet, D., Merckelbach, H., Giesbrecht, T., \& Broers, N. (2014). Night-time experiences and daytime dissociation: A path analysis modeling study. Psychiatry Research, 216(2), 236-241. doi:10.1016/j.psychres.2013.12.053

Vermetten, E., Dorahy, M., \& Spiegel, D. (2007). Traumatic dissociation: Neurobiology and treatment. Washington, DC: American Psychiatric Publishing.
Verplanken, B., Friborg, O., Wang, C. E., Trafimow, D., \& Woolf, K. (2007). Mental habits: metacognitive reflection on negative self-thinking. Journal of Personality and Social Psychology, 92(3), 526-541. doi:10.1037/0022-3514.92.3.526

Vogel, M., Spitzer, C., Barnow, S., Freyberger, H. J., \& Grabe, H. J. (2006). The role of trauma and PTSD-related symptoms for dissociation and psychopathological distress in inpatients with schizophrenia. Psychopathology, 39(5), 236-242. doi:10.1159/000093924

Walker, M. P., \& van der Helm, E. (2009). Overnight therapy? The role of sleep in emotional brain processing. Psychological Bulletin, 135(5), 731-748. doi:10.1037/a0016570

Watkins, E. R. (2008). Constructive and unconstructive repetitive thought. Psychological Bulletin, 134(2), 163-206.

Watson, D. (2001). Dissociations of the night: Individual differences in sleep-related experiences and their relation to dissociation and schizotypy. Journal of Abnormal Psychology, 110(4), 526535. doi:10.1037/0021-843X.110.4.526

Watson, D. (2003). Investigating the construct validity of the dissociative taxon: Stability analyses of normal and pathological dissociation. Journal of Abnormal Psychology, 112(2), 298305.

Watts, F. N., Coyle, K., \& East, M. P. (1994). The contribution of worry to insomnia. British Journal of Clinical Psychology, 33(2), 211-220

Watts, F. N., East, M. P., \& Coyle, K. (1995). Insomniacs' perceived lack of control over sleep. Psychology and Health, 10(2), 8195.

Wells, A. (2005). The metacognitive model of GAD: Assessment of meta-worry and relationship with DSM-IV generalized anxiety disorder. Cognitive Therapy and Research, 29(1), 107-121. doi:10.1007/s10608-005-1652-0

Wells, A., \& Morrison, A. P. (1994). Qualitative dimensions of normal worry and normal obsessions: A comparative study. Behavior Research and Therapy, 32(8), 867-870. doi:10.1016/0005-7967(94)90167-8

Yargic, L. I., Tutkun, H., \& Sar, V. (1995). Reliability and validity of the Turkish version of the Dissociative Experiences Scale. Dissociation, 8(1), 10-13.

Yilmaz, A. E., Gencoz, T., \& Wells, A. (2008). Psychometric Characteristics of the Penn State Worry Questionnaire and Metacognitions Questionnaire-30 and Metacognitive Predictors of Worry and Obsessive-Compulsive Symptoms in a Turkish Sample. Clinical Psychology \& Psychotherapy, 15(6), 424-439. doi:10.1002/cpp.589

Yook, K., Kim, K. H., Suh, S. Y., \& Lee, K. S. (2010). Intolerance of uncertainty, worry, and rumination in major depressive disorder and generalized anxiety disorder. Journal of Anxiety Disorders, 24(6), 623-628. doi:10.1016/j.janxdis.2010.04.003

Yu, C. K. C. (2010). Dream Intensity Profile as an indicator of the hysterical tendencies to dissociation and conversion. Dreaming, 20(3), 184-198. doi:10.1037/a0020421

Zeitlhofer, J., Schmeiser-Rieder, A., Tribl, G., Rosenberger, A., Bolitschek, J., Kapfhammer, G., ... Kunze, M. (2000). Sleep and quality of life in the Austrian population. Acta Neurologica Scandinavica, 102(4), 249-257. 